\title{
Activation of Neuronal NMDA Receptors Triggers Transient ATP-Mediated Microglial Process Outgrowth
}

\author{
Lasse Dissing-Olesen, Jeffrey M. LeDue, Ravi L. Rungta, Jasmin K. Hefendehl, Hyun B. Choi, and Brian A. MacVicar \\ Brain Research Centre, University of British Columbia, Vancouver, British Columbia V6T 2B5, Canada
}

Microglia are morphologically dynamic cells that rapidly extend their processes in response to various stimuli including extracellular ATP. In this study, we tested the hypothesis that stimulation of neuronal NMDARs trigger ATP release leading to communication with microglia. We used acute mouse hippocampal brain slices and two-photon laser scanning microscopy to study microglial dynamics and developed a novel protocol for fixation and immunolabeling of microglia processes. Similar to direct topical ATP application in vivo, short multiple applications of NMDA triggered transient microglia process outgrowth that was reversible and repeatable indicating that this was not due to excitotoxic damage. Stimulation of NMDAR was required as NMDAR antagonists, but not blockers of AMPA/kainate receptors or voltage-gated sodium channels, prevented microglial outgrowth. We report that ATP release, secondary to NMDAR activation, was the key mediator of this neuron-microglia communication as both blocking purinergic receptors and inhibiting hydrolysis of ATP to prevent locally generated gradients abolished outgrowth. Pharmacological and genetic analyses showed that the NMDA-triggered microglia process extension was independent of Pannexin 1, the ATP releasing channels, ATP release from astrocytes via connexins, and nitric oxide generation. Finally, using whole-cell patch clamping we demonstrate that activation of dendritic NMDAR on single neurons is sufficient to trigger microglia process outgrowth. Our results suggest that dendritic neuronal NMDAR activation triggers ATP release via a Pannexin 1-independent manner that induces outgrowth of microglia processes. This represents a novel uncharacterized form of neuron-microglial communication mediated by ATP.

Key words: ATP purinergic receptors; microglia process motility; NMDA glutamate receptors; Pannexin; synaptic surveillance

\section{Introduction}

Microglia, the primary immune effectors in the brain, exhibit a ramified morphology with motile processes that survey their surroundings (Nimmerjahn et al., 2005). Ramified microglia are responsible for synaptic pruning (Paolicelli et al., 2011) and sculpting of synaptic connections during development (Schafer et al., 2012; Bialas and Stevens, 2013). In the adult CNS the motility of microglial processes decreases upon contact with synapses (Wake et al., 2009), and dendritic spines are significantly

\footnotetext{
Received Jan. 28, 2014; revised May 25, 2014; accepted June 22, 2014.

Author contributions: L.D.-O., R.L.R., J.K.H., H.B.C., and B.A.M. designed research; L.D.-O., R.L.R., J.K.H., and H.B.C. performed research; L.D.-O., J.M.L., and H.B.C. analyzed data; L.D.-O., J.M.L., R.L.R., J.K.H., H.B.C., and B.A.M. wrote the paper.

This work was supported by operating grants from the Canadian Institutes of Health Research (CIHR Funding reference numbers 8545 and 10677 TCE-117869 in the framework of the ERA-NET NEURON), a Canada Research Chair, a Deutsche Forschungsgemeinschaft postdoctoral fellowship (J.K.H.), a CIHR studentship award (R.L.R.), a Heart and Stroke Studentship Award (L.D.-0.), and the Fondation Leducq. We thank Drs. Moises Freitas-Andrade, John Bechberger, and Christian Naus, Department of Cellular and Physiological Sciences, University of British Columbia, Vancouver, Canada, for help with the Panx1 K0 mice; Drs. Matthieu Vanni, Xiao-Yan Jiang, Timothy Murphy, Department of Psychiatry, University of British Columbia, Vancouver, Canada, for help with the Emx-GCaMP3 mice; Drs. Silvia Penuela and Dale W. Laird, Department of Anatomy and Cell Biology, University of Western Ontario, London, Canada, for generously providing the antibody against Panx1; Jeannie Poblete and Dr. David Julius, Department of Physiology, University of California San Francisco, San Francisco, California, for generously providing the antibody against P2Y12; and Drs. Kelly Dissing-0lesen and Louis-Philippe Bernier for stimulating discussions about the study and for excellent feedback on this manuscript.

The authors declare no competing financial interests.

Correspondence should be addressed to Brian A. MacVicar, Brain Research Centre, 2211 Wesbrook Mall, Vancouver, BC V6T 2B5, Canada. E-mail: bmacvicar@brain.ubc.ca.

DOI:10.1523/JNEUROSCI.0405-14.2014

Copyright $\odot 2014$ the authors $\quad 0270-6474 / 14 / 3410511-17 \$ 15.00 / 0$
}

more likely to be eliminated following contact with microglial processes (Tremblay et al., 2010). However, previous studies examining the link between neuronal activity and microglia process dynamics in rodents have yielded contradictory findings. Blocking synaptic transmission did not alter microglial process motility, whereas increasing neuronal activity by blocking inhibition (Nimmerjahn et al., 2005; Fontainhas et al., 2011) but not by electrophysiological stimulation (Wu and Zhuo, 2008) increased motility and extension of the microglial processes. Thus, identifying the molecular cue(s) mediating microglia responses and determining how the release of these signals are being triggered would be an important contribution to the overall understanding of neuron-microglia communication in the adult brain.

ATP is an important molecular chemoattractant mediating "find-me" signals for immune cells (Elliott et al., 2009; Chekeni et al., 2010) and several studies have demonstrated that microglial processes rapidly extend toward local tissue damage or locally applied ATP (Davalos et al., 2005; Haynes et al., 2006). P2Y12 receptors are selectively expressed by microglia in the brain (Sasaki et al., 2003; Hickman et al., 2013) and are the critical purinergic receptors for microglial process extension in vivo and in vitro (Haynes et al., 2006; Orr et al., 2009; Ohsawa et al., 2010). In addition ATP metabolites such as adenosine may help establish the gradient for directed microglia extension (Ohsawa et al., 2012). These studies highlight ATP and its derivatives are signaling molecules that, when released, can mediate microglial process extension. ATP release via open Pannexin 1 (Panx1) channels 
(Huang et al., 2007; Chekeni et al., 2010; Li et al., 2011) has been observed in many cells. Repetitive stimulation of NMDARs triggered neuronal Panx1 channel opening in rodents (Thompson et al., 2008). In zebrafish larvae, NMDA uncaging triggered microglial process extension (Sieger et al., 2012) while repetitive glutamate uncaging mediated Panxl opening and promoted an ATP-induced neuron-microglia contact (Li et al., 2012). Thus, we investigated whether NMDAR activation in the adult rodent brain could evoke signaling to microglia and whether this form of communication relied on Panx1. To address these questions, an NMDAR stimulation paradigm in acute brain slices from mice was developed that allowed for pharmacological interventions during timelapse imaging of changes in microglia morphology. Furthermore, a novel protocol for fixation and immunolabeling of dynamic processes in whole-brain slices was developed to visualize microglial morphology in brain slices from Panx1deficient mice subjected to our NMDAR stimulation paradigm. Finally, to demonstrate that microglia responded to selective stimulation of neuronal NMDAR we activated NMDAR on single, voltageclamped neurons and found this triggered microglia process outgrowth.

\section{Materials and Methods}

Animals. CX3CR1 ${ }^{\text {EGFP/EGFP }}$ mice on a BALB/c background and CX3CR $1^{\mathrm{EGFP} /+}$ on C57BL/6 background (Jung et al., 2000) were bred and housed under controlled conditions (12 h light/ dark cycle) with water and food ad libitum. Panx1 knock-out (KO) mice on C57BL/6 background (Qu et al., 2011) and age-matched C57BL/6 wildtype (WT) mice were a gift from Dr. Christian Naus (University of British Columbia, Vancouver, BC, Canada). Emx-GCaMP3 mice (produced by crossing B6.129S2-Emx1 ${ }^{\mathrm{tml}(\mathrm{cre}) \mathrm{Krj} / \mathrm{J}}$ strain with B6;129S-Gt(ROSA)26Sor ${ }^{\text {tm38(CAG-GCaMP3)Hze } / J}$ strain; Gorski et al., 2002) were a gift from Dr. Timothy Murphy (University of British Columbia, Vancouver, BC, Canada). Note that EGFP is introduced as a "knock-in," thus the CX3CR1 gene encoding the fractalkine receptor is replaced with the gene encoding for EGFP (i.e., mice heterozygous for EGFP are CX3CR ${ }^{-1+}$ while mice homozygous for EGFP are fractalkine receptor $\mathrm{KO}$, CX3CR $1^{-1-}$ ).

Slice preparation and maintenance. Mice (40-120 d, both males and females) were anesthetized with halothane and decapitated according to protocols approved by the University of British Columbia committee on animal care. The brains were removed and sliced in an ice-cold solution containing the following (in mM): $120 \mathrm{~N}$-methyl-D-glucamine, $2.5 \mathrm{KCl}$, $25 \mathrm{NaHCO}_{3}, 1 \mathrm{CaCl}_{2}, 7 \mathrm{MgCl}_{2}, 1.2 \mathrm{NaH}_{2} \mathrm{PO}_{4}, 2$ D-glucose, 2.4 sodium pyruvate, and 1.3 sodium $\mathrm{L}$-ascorbate, which was constantly oxygenated with $95 \% \mathrm{O}_{2}$ and $5 \% \mathrm{CO}_{2}$. The brains were sliced horizontally $(300 \mu \mathrm{m}$ thick) using a vibratome (Leica VT1200S) with disposable razor blades (Canemco \&Marivac) and incubated for $1 \mathrm{~h}$ at room temperature (RT) in oxygenated artificial CSF (ACSF) containing the following (in mM): 126 $\mathrm{NaCl}, 2.5 \mathrm{KCl}, 26 \mathrm{NaHCO}_{3}, 2.0 \mathrm{CaCl}_{2}, 2 \mathrm{MgCl}_{2}, 1.25 \mathrm{NaH}_{2} \mathrm{PO}_{4}$, and 10
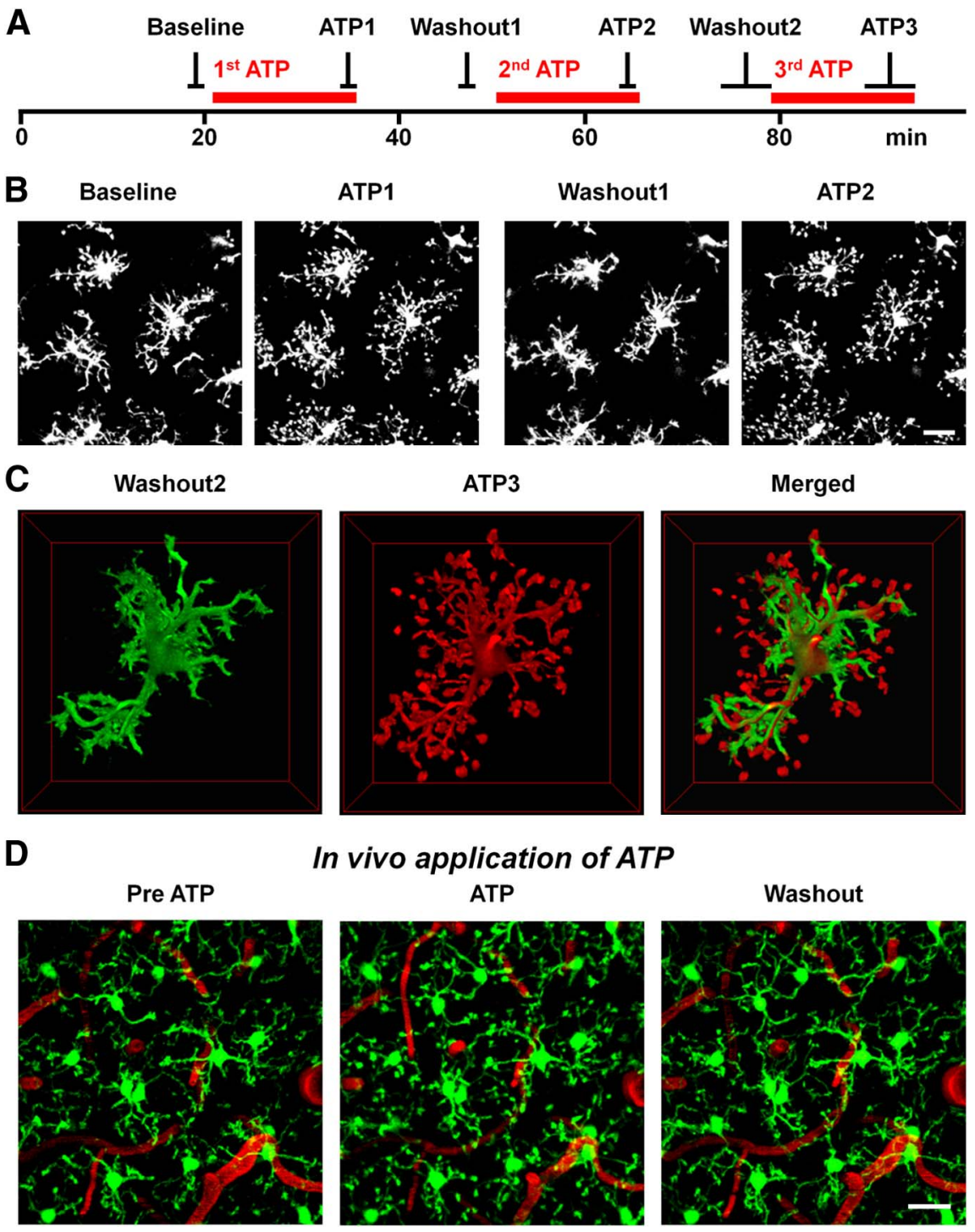

\section{In vivo application of ATP}

ATP
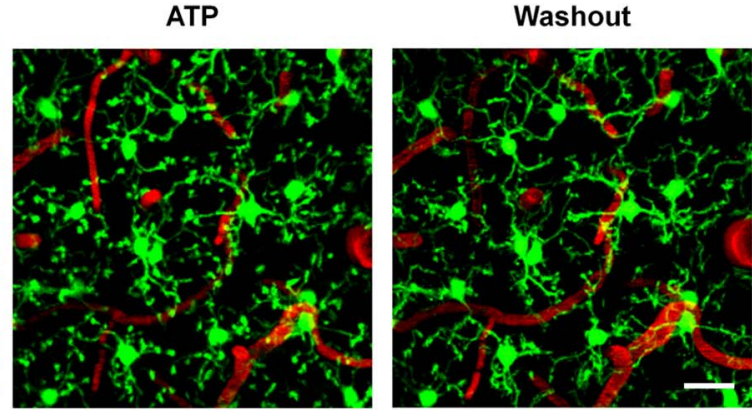

Figure 1. Patterns of microglial process outgrowth induced by ATP in slices and in vivo. $\boldsymbol{A}$, Time line for image acquisition and ATP applications in slices. $\boldsymbol{B}$, Bath application of ATP (500 $\mu \mathrm{m} ; 15 \mathrm{~min})$ induced microglial process outgrowth in slices, which is (W of the $x$-y plane. Scale bar, $20 \mu \mathrm{m}$. D. Microglial process outgrowth in vivo following topical application of ATP (10 mm) to the intact cortex. Note that ATP induced similar morphological changes in vivo as compared within slices that reversed during Washout. Blood vessels are seen in red. Scale bar, $20 \mu \mathrm{m}$.

D-glucose, $\mathrm{pH} 7.3-7.4$, osmolarity 300 mOsm. Experiments were performed at RT with continuous perfusion $(3 \mathrm{ml} / \mathrm{min}$ ) of oxygenated ACSF. For the experiments involving NMDA application the concentration of $\mathrm{MgCl}_{2}$ was either reduced to $0.6 \mathrm{~mm}$ or increased to $6 \mathrm{~mm}$ (the $\mathrm{NaCl}$ concentration was adjusted to balance osmolarity and $\mathrm{NaH}_{2} \mathrm{PO}_{4}$ was omitted from the high $\mathrm{Mg}^{2+}$ solution) and $10 \mu \mathrm{M}$ glycine was added.

Fixation and immunolabeling of brain slices using modified methods. Brain slices were fixed by immersion in $4 \%$ PFA at $80^{\circ} \mathrm{C}$ for $2 \mathrm{~min}$ and rinsed in $0.1 \mathrm{M}$ PBS. The 300 - $\mu \mathrm{m}$-thick slices were immunolabeled free floating and each step was performed in $0.1 \mathrm{M}$ PBS with $20 \%$ DMSO and $2 \%$ Triton X-100. In short, slices were blocked for $24 \mathrm{~h}$ in $10 \%$ goat serum, incubated for $8 \mathrm{~d}$ with a polyclonal rabbit antibody against mouse ionized calcium binding adaptor molecule 1 (Iba1; $0.5 \mu \mathrm{g} / \mathrm{ml}$ ) or a polyclonal rabbit antibody against mouse P2Y12 (Haynes et al., 2006) and $2.5 \%$ goat serum, washed for $24 \mathrm{~h}$, incubated for $6 \mathrm{~d}$ with a polyclonal 
A Baseline $1^{\text {st }}$ NMDA

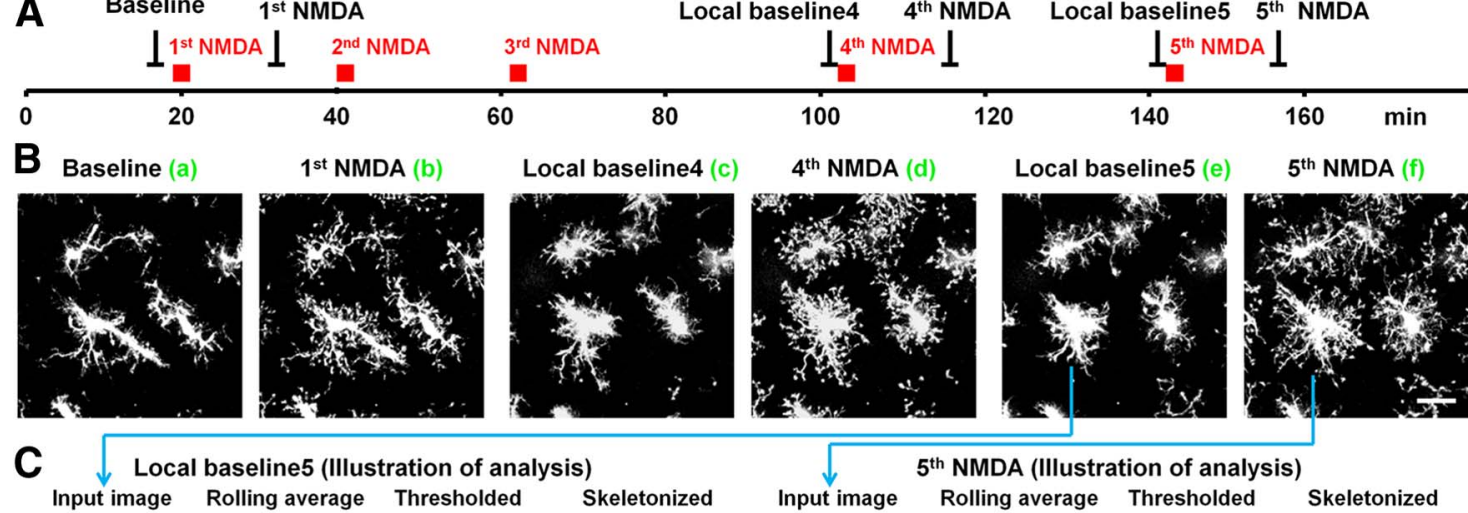

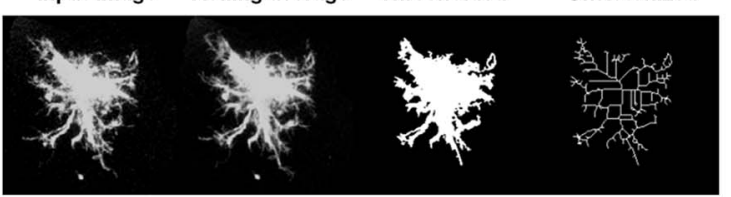

D1

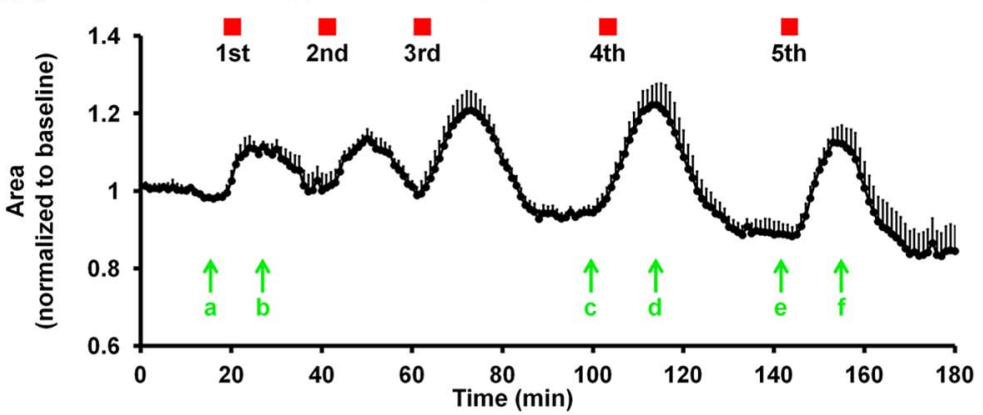

D3
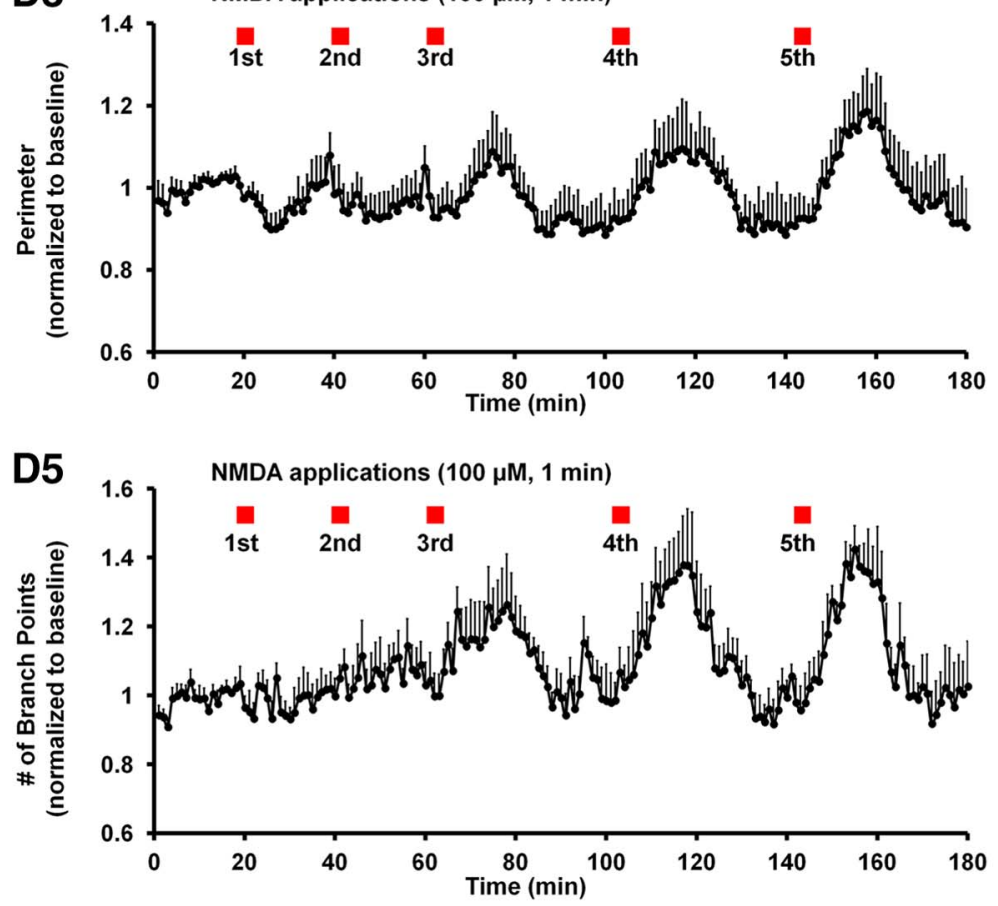

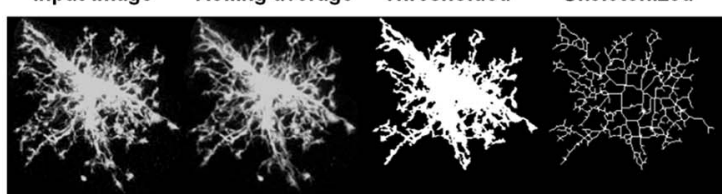

D2

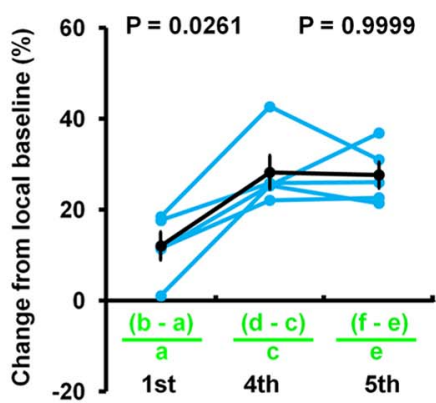

D4 Perimeter

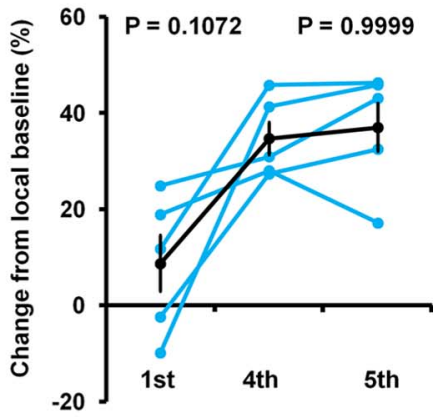

D6 \# of Branch Points

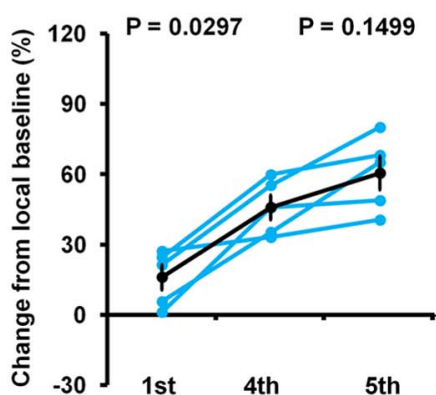

Figure 2. Microglial process outgrowth triggered by NMDA was repeatable and reversible. $\boldsymbol{A}$, Time line for image acquisition during NMDA applications. $\boldsymbol{B}$, Multiple bath applications of NMDA (100 $\mu \mathrm{m} ; 1 \mathrm{~min}$ /application) consistently triggered microglial process outgrowth illustrated with this series of images obtained at the different time points before and following multiple NMDA applications as indicated in $\boldsymbol{A}$. The sample images from this time series show that the process outgrowth was reversible after each application and was induced again when NMDA was reintroduced each of these five times. Scale bar, $20 \mu \mathrm{m}$. C, Illustration of step-by-step analysis of the microglial cell indicated with the arrows from $\boldsymbol{B}$. D, Graphic depiction of quantified microglial morphology for different parameters over time with NMDA applications indicated by red markers. D1, D3, D5, Show quantification of the surface area of the thresholded images, the perimeter of the thresholded images, and the number of branch points of the skeletonized images, respectively, with the values normalized to the baseline (average of the first 15 min) and graphed as the mean + SEM. D2, D4, D6, Show the quantification of the morphological changes following the first, fourth, and fifth NMDA applications from the respective local baseline (defined as the 5 min (Figure legend continues.) 


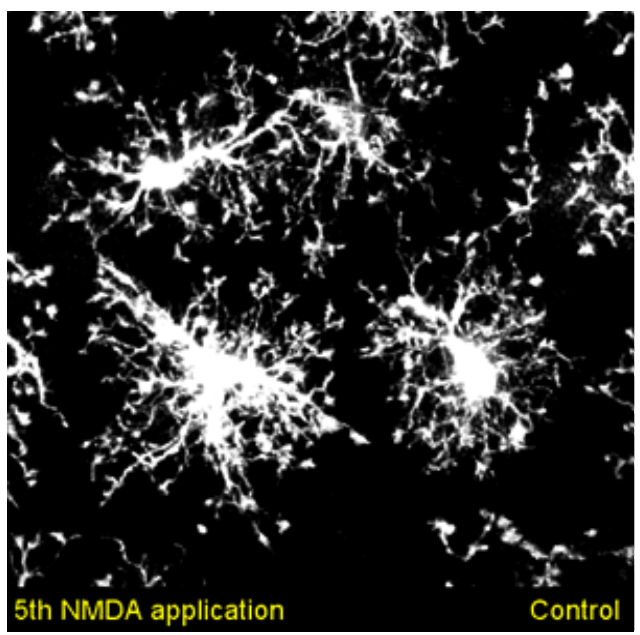

Movie 1. Microglial process outgrowth triggered by NMDA. Multiple bath applications of NMDA (100 $\mu \mathrm{m} ; 1 \mathrm{~min} /$ application) triggered microglial process outgrowth. Time-lapse imaging of morphological changes following the first, fourth, and fifth NMDA applications from the respective local baselines (defined as the $5 \mathrm{~min}$ before the respective NMDA application) to 15 min following the NMDA application. The red bars that appear during the movie indicate the time of NMDA applications. Note the NMDA-triggered extension of existing processes, sprouting of new branches, and formation of bulbous tips that are apparent following the fourth and the fifth NMDA applications.

goat-anti-rabbit IgG antibody conjugated with Alexa $594(1 \mu \mathrm{g} / \mathrm{ml})$ and $2.5 \%$ goat serum, and rinsed in $0.1 \mathrm{M}$ PBS. Before imaging the slices were mounted in FluorSave reagent on specially made microscope slides (Fisher Scientific) with the cover glass elevated $300 \mu \mathrm{m}$ above the slide. This protocol gave us six unique capabilities. First, we could fix the tissue at any given time point during real-time imaging (i.e., following a lesion or during ATP or NMDA applications) thereby obtaining a snapshot of the morphology at the exact time of fixation. Second, we could run simultaneous experiments under the same conditions with several slices prepared from the same brain (i.e., one slice subjected to ATP or NMDA applications and one slice serving as a nontreated control that was fixed simultaneously). Third, we could image microglia morphology at specific time points without live cell illumination with the ultrafast infrared laser for two-photon imaging thereby ruling out potential contributions of laser-induced phototoxicity in our paradigm. Fourth, the fixation was fast enough to allow us to immunolabel target proteins and link their cellular location to the exact cellular morphology. Fifth, we could investigate the cellular responses in a large brain region at precisely the same time point (i.e., microglial responses to five NMDA applications across the stratum radiatum). Sixth, we could image cells after fixation and immunolabeling at comparable and defined depths within brain slices. The decision to fix the slices 8 min post the fifth NMDA application was based on an early estimate of the peak outgrowth following fifth NMDA applications. We named this modified method StaiNing of dynAmic ProcesseS in HOt-fixed Tissue, or SNAPSHOT.

Surgery for in vivo imaging. A round cranial window (2 mm diameter) was installed under general anesthesia (fentanyl, $0.05 \mathrm{mg} / \mathrm{kg}$; midazolam, $5 \mathrm{mg} / \mathrm{kg}$; medetomidine, $0.50 \mathrm{mg} / \mathrm{kg}$ ). The anesthetized mice were secured on a modified stereotactic frame while placed on a heating pad. The skin and the periosteum were removed to expose the skull. Lines forming a circle $(0.5 \mathrm{~mm}$ lateral of $-0.5 \mathrm{~mm}$ bregma $)$ were gently drilled

(Figure legend continued.) before the respective NMDA application and indicated by a, $c$, and e in D1) to the max value within 15 min following NMDA application (indicated by b, d, and fin D1). Each data point is represented with a blue dot and data points from the same experiments are connected with blue lines. The mean \pm SEM is illustrated in black. The experiments were performed in low $\mathrm{Mg}^{2+}(0.6 \mathrm{mM})$ and in the presents of glycine $(10 \mu \mathrm{M})$. Repeated-measures ANOVA with Bonferroni's multiple-comparison post-test was used for statistical comparison of the change from local baseline between the groups $(n=5)$. onto the skull surface. The respective portion of the skull was removed and the brain was kept moist at all times using surgical gel sponges in PBS (GelitaSpon). A custom-made titanium ring (14 mm diameter) was then sealed onto the skull above the cranial window with light-curing dental cement (Heraeus) to secure the mouse to a custom-made head fixation plate during imaging (Hefendehl et al., 2012). Finally, the dura mater was carefully removed.

Local application of ATP. Two electrodes (tip resistance 4-6 M $\Omega$ ) were placed $100 \mu \mathrm{m}$ apart at $150 \mu \mathrm{m}$ below the surface of the slice using bright-field illumination as guidance. Positive pressure $(0.05 \mathrm{psi})$ was applied before entering the tissue and continuously throughout the experiments. One electrode $(\# 1)$ contained ACSF and served as a reference while the other electrode (\#2) contained ACSF with 4 mM ATP. Fifty micrometers or $200 \mu \mathrm{M}$ of the selective ectonucleotidases inhibitor ARL 67156 trisodium salt (ARL) was added to the ACSF in the bath. Alexa 594 hydrazide-sodium salt $(100 \mu \mathrm{M})$ was added to the internal solution of each electrode for visualization of the tip. Image acquisition was initiated within 5 min of placement of the electrodes (defined as time 0 for quantification). Microglial process outgrowth toward the tip of the electrode was quantified as $F / F_{0}$ at $500-550 \mathrm{~nm}$ emission within circles (radius of $50 \mu \mathrm{m})$ centered at the tip of each electrode $(F=$ fluorescence intensity at time $x, F_{0}=$ fluorescence intensity at time 0$)$.

Astrocytic dye coupling. Astrocytes were voltage clamped at $-80 \mathrm{mV}$ with an intracellular solution containing the following (in $\mathrm{mM}$ ): 124 potassium gluconate, $4 \mathrm{MgCl}_{2}, 10$ HEPES, 1 EGTA, 4 potassium ATP, 0.4 sodium GTP, $10 \mathrm{Na}_{2}$ creatine $\mathrm{PO}_{4}, 0.1$ Alexa 488 hydrazide-sodium salt, $\mathrm{pH}$ adjusted to 7.2, with $\mathrm{KOH}$ and osmolarity adjusted to 290-300 mOsm. Carbenoxolone (CBX; $100 \mu \mathrm{M}$ ) was perfused onto slices $25 \mathrm{~min}$ before whole-cell configuration and throughout the experiments. To ensure proper dialysis of the internal solution, image acquisition was not initiated before $20 \mathrm{~min}$ after whole-cell configuration. Astrocytes were visualized before patching by staining brain slices with sulforhodamine 101, a specific marker for astrocytes (Nimmerjahn et al., 2004; Kafitz et al., 2008).

Neuronal patch-clamping experiment. CA1 pyramidal neurons were voltage clamped at $-70 \mathrm{mV}$ using the blind patch-clamp method (Castañeda-Castellanos et al., 2006). Patch electrodes (tip resistance 4-6 $\mathrm{M} \Omega$ ) were pulled from $1.5 \mathrm{~mm}$ outer diameter thin-walled, glass capillaries (World Precision Instruments) using a Flaming-Brown micropipette puller (Sutter Instruments). The electrodes were lowered in the stratum oriens and aimed to approach the stratum pyramidale at 140 $160 \mu \mathrm{m}$ below the surface of the slice. Positive pressure ( $0.5 \mathrm{psi})$ was applied before entering the bath and kept until contact with a pyramidal cell. The intracellular solution contained the following (in mM): 4 potassium ATP, 108 potassium gluconate, $2 \mathrm{MgCl}_{2}, 10 \mathrm{HEPES}, 1$ EGTA, 0.3 sodium GTP, 8 sodium gluconate, $8 \mathrm{KCl}$, and 0.1 Alexa 594 hydrazidesodium salt, $\mathrm{pH}$ adjusted to 7.2 , with $\mathrm{KOH}$ and osmolarity adjusted to 285-290 mOsm. MK-801 (1 mM) was added to the intracellular solution. The blind patch-clamp method was chosen as it allowed for unbiased selection of CA1 pyramidal neurons and for targeting cells deep in the tissue.

Slice imaging. A two-photon scanning microscope (Coherent Chameleon Ultra II laser coupled to a Zeiss LSM510 Axioskop 2 microscope with a Zeiss $40 \times-\mathrm{W} / 1.0 \mathrm{NA}$ objective) was used to image live and fixed hippocampal brain slices. Microglial cells were imaged in the stratum radiatum of the CA1 region at $150 \pm 25 \mu \mathrm{m}$ below the surface of the slice. Images for time-lapse analysis were collected at $512 \times 512$ pixels using 4 -line averaging and acquired as a time series of stacks $(z=15 ; 2 \mu \mathrm{m}$ steps with the soma of the microglial cell(s) of interest in the middle of the stack) with a total scan time of $\sim 1$ min per stack. Images for $3 D$ reconstruction were acquired as stacks of 75-90 images using 8-line averaging and stepping $0.5 \mu \mathrm{m}$ in the $z$-axis between frames. EGFP and GCaMP3 were excited at $920 \mathrm{~nm}$ and the emission was detected with a photomultiplier tube after passing through a $500-550 \mathrm{~nm}$ emission filter. The same filter and detector was also used for image acquisition during the patch-clamp experiments with Alexa 488, which was excited at $800 \mathrm{~nm}$. For horizontal cross sections of the stratum radiatum, images of fixed slices were acquired as stacks ( $z=2512 \mu \mathrm{m}$ steps) with $\sim 20 \%$ overlap with its neighboring images to allow alignment for tiling images. Alexa 594 and sulforhodamine 101 were imaged using $800 \mathrm{~nm}$ excitation and a 


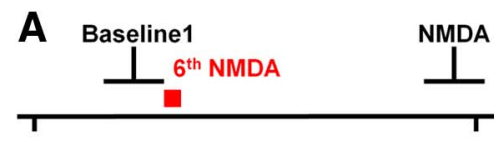

180

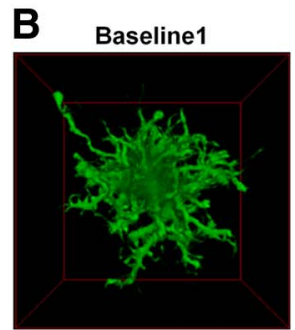

C1 bottom view

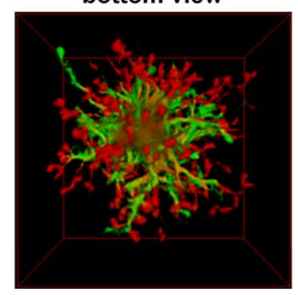

C2

'Baseline2' (green) merged with 'ATP' (red) bottom view

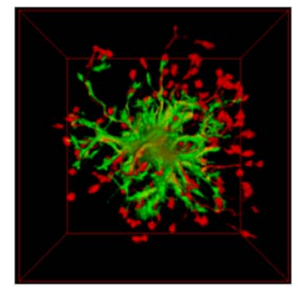

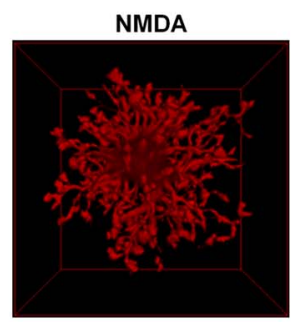

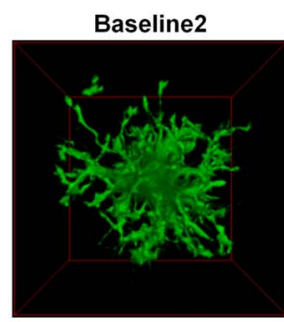

top view

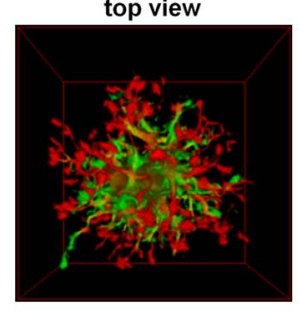

top view

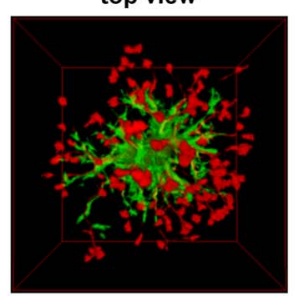

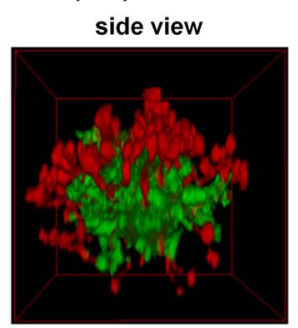

side view

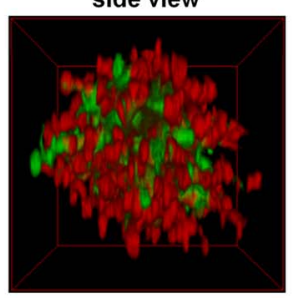

side view
Baseline2

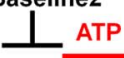

220
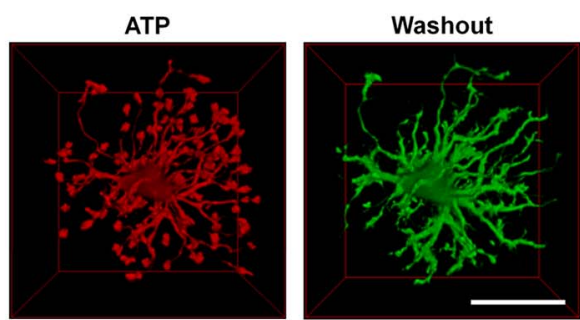

D
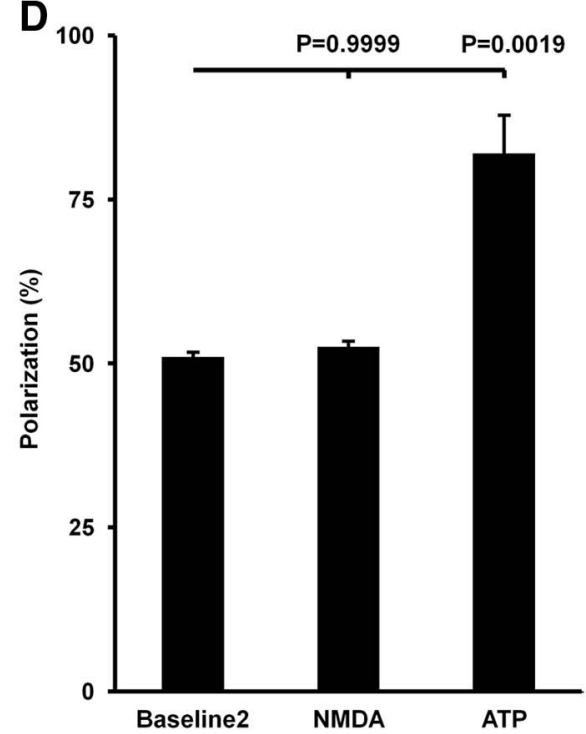

Figure 3. NMDA triggered a nonpolarized outgrowth of microglia processes in contrast to ATP application. $A$, Time line for image acquisition to examine NMDA versus ATP-induced outgrowth (note, that this is the sixth NMDA application). $\boldsymbol{B}, 3 \mathrm{D}$ reconstructions (shown as bottom view, $x$-y plane) of a microglial cell at five different time points as indicated in $\boldsymbol{A}$. Note, in Washout (immediately after termination of ATP application) the microglial processes were still extended while the bulbous tips were collapsed. Scale bar, $20 \mu \mathrm{m}$. C, Merging of the images before (green) and following (additional portions of the cell are in red) either from NMDA (C1) or ATP application (C2). The merged 3D reconstructions are shown as bottom views ( $x$-y plane), top view ( $x$-y plane), and side views (z-y plane). Note, that outgrowth induced by NMDA-triggered ATP release is nonpolarized (uniform distribution of red bulbous tips) while the red bulbous tips are polarized toward the top (surface of the slice) during ATP application. D, Bar graph depicting the microglial cell polarization in different conditions. The cell's center of mass at Baseline1 was used to determine changes in polarization (total fluorescence above the center of mass/total fluorescence below the center of mass) of the cell at the indicated time points. The groups were compared using repeated-measures ANOVA with Bonferroni's multiple-comparison post-test $(n=3)$.

$600-660 \mathrm{~nm}$ emission filter. Lesions were induced by exposure of high laser power illumination to a restricted area. Nonsaturated images (all pixels $<255)$ and images through the whole-brain slice $(z=151 ; 2 \mu \mathrm{m}$ steps with auto $z$ brightness correction, ZEN 2012 software) were acquired using a Zeiss LSM7MP-AX10 microscope with a Zeiss $20 \times-\mathrm{W} / 1.0$ NA objective.

In vivo imaging. In vivo imaging was performed on anesthetized mice (fentanyl, $0.05 \mathrm{mg} / \mathrm{kg}$; midazolam, $5 \mathrm{mg} / \mathrm{kg}$; medetomidine, $0.50 \mathrm{mg} / \mathrm{kg}$ ) using a custom-built two-photon microscope equipped with a Coherent Chameleon Ultra II laser and a Zeiss $40 \times-W / 1$ NA objective. Texas Red dextran (Invitrogen; $70 \mathrm{kDa} ; 12.5 \mathrm{mg} / \mathrm{ml}$ in sterile PBS) was injected intravenously, providing a fluorescent angiogram. The mice were secured under the microscope by fitting the titanium ring in a custom-built head fixation apparatus (Hefendehl et al., 2012) connected to a motorized $x-y$ stage (Sutter Instruments). EGFP and Texas Red were imaged simultaneously using $920 \mathrm{~nm}$ excitation and were detected via nondescanned detectors and ET525/50m-2P and ET605/70m-2P emission filters, respectively (Chroma Technology). Images were collected at $512 \times 512$ pixels without averaging and acquired as stacks $(z=40 ; 1 \mu \mathrm{m}$ steps) at a depth of 100-140 $\mu \mathrm{m}$ below the cortical surface. ACSF was continuously perfused across the cortical surface $(3 \mathrm{ml} / \mathrm{min})$ using a custom-made perfusion system that was designed to fit within the tita- nium ring and allowed delivery and washout of ATP similar to the application used for slices. Laser power was kept constant for each experiment and did not exceed $45 \mathrm{~mW}$.

Image processing and analysis. All images were processed using ImageJ (1997-2013; NIH; http://imagej.nih.gov/ij/). The following steps were used to prepare the time-lapse images for analysis unless otherwise indicated: (1) concatenation of the time series, (2) application of a median filter, (3) $z$-projection by maximum intensity of each stack (every time point), and (4) alignment of all images in an $x-y$ plane, thereby generating a $2 \mathrm{D}$ time series for further analysis. To quantify the morphological changes occurring over time we generated an unbiased and fully automated program using MATLAB R2012b inspired by Kozlowski and Weimer (2012). In short, only cells with their soma within the middle five images of each stack were included in the analysis. Each cell was subjected to five frame rolling average and made binary (threshold calculated by Otsu's method, MATLAB graythresh function). The thresholded cell was identified as the largest connected region and its cross-sectional area and perimeter were quantified. Additional quantifications were performed by determining the number of branch points using a "skeletonized" model of the cell (i.e., modeled by straight lines based on the shape of the largest connected region) as previously used by others for quantifying changes of microglial processes (Fontainhas et al., 2011). We found that 
A1 CX3CR1 $1^{\text {t+ }}$ Local baseline 5 . $5^{\text {th }}$ NMDA

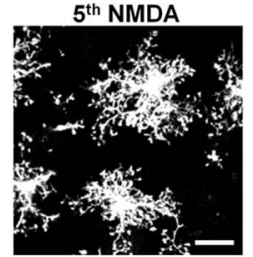

A2

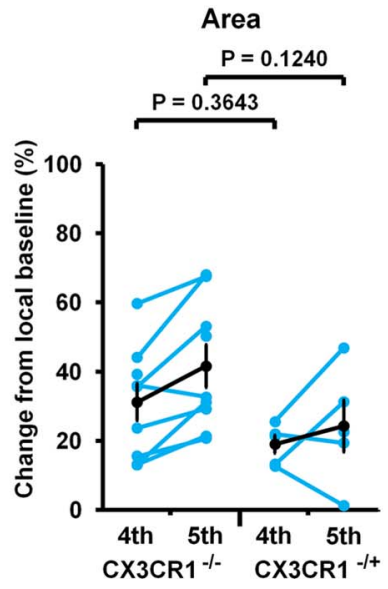

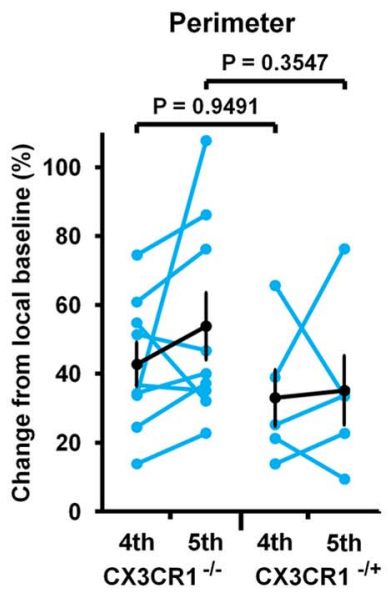

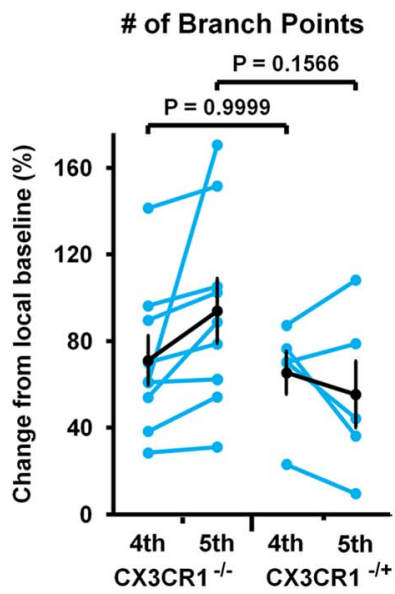

Figure 4. Outgrowth occurred independently of CX3CR1 expression. Multiple bath applications of NMDA, using the paradigm presented in Figure 2, led to a similar outgrowth in slices from CX3CR1 K0 (CX3CR1 ${ }^{-/-}$) and CX3CR1 heterozygous (CX3CR1 ${ }^{-/+}$) mice. A1, Examples of outgrowth following the fifth NMDA application compared with the local baseline5 in a slice from a CX3CR ${ }^{-1+}$ mouse. Scale bar, $20 \mu \mathrm{m}$. A2, Graphic depiction of changes from the local baseline following the fourth and fifth NMDA application, determined as illustrated in Figure 2, for both $\mathrm{CX} 3 \mathrm{CR} 1^{-1-}$ and $\mathrm{CX} 3 \mathrm{CR} 1^{-1+}$ mice. Each data point is represented with a blue dot and data points from the same experiments are connected with blue lines. The mean \pm SEM is illustrated in black. One-way ANOVA with Bonferroni's multiple-comparison post-test was used for statistical comparison of the change from baseline following the fourth NMDA application in CX3CR1 - -

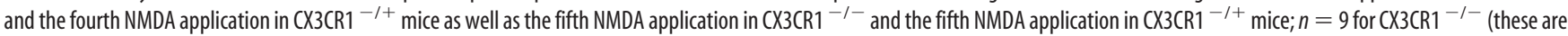
separate experiments than those depicted in Fig. 2D) and $n=5$ for $\left(X 3 C R 1^{-1+}\right.$.

applying a rolling averaging step before thresholding improved the preservation of the connectivity of thin processes to the soma. The images acquired for $3 \mathrm{D}$ reconstruction were subjected to subtraction of the mean value of a region defined as background, aligned, and subjected to auto-adjustment of brightness and contrast. The center of mass was determined by the BoneJ plugin; "Moments of Inertia" and 3D reconstructions were generated using ImageJ's 3D viewer. Nonsaturated images were pseudocolored by intensity using ImageJ's look-up tables (fire) and cross sections of the stratum radiatum were reconstructed of up to six images using the MosaicJ plugin.

Statistics. Statistical analyses were performed using GraphPad Prism version 6.0 for Mac. Gaussian distributions were assumed for all experiments and $n$ values represent the number of animals. For multiple comparisons multiplicity-adjusted $p$ values are indicated on the respective figures when appropriate, otherwise the $p$ values were indicated by ${ }^{*} p<$ $0.05,{ }^{* *} p<0.01$, and ${ }^{* * *} p<0.001$.

Western blotting. Additional brain slices from mice, from which slices were used for imaging and fixation, were homogenized using lysis buffer containing the following (in mM): 100 Tris (pH 7.0), 2 EGTA, 5 EDTA, 30 $\mathrm{NaF}, 20$ sodium pyrophosphate, and $0.5 \%$ NP40 with phosphatase and protease inhibitors (Roche) and centrifuged at 13,000 $\times g$ for $20 \mathrm{~min}$ at $4^{\circ} \mathrm{C}$. Protein concentrations of the lysates were determined by Bradford assay using a DC protein assay dye (Bio-Rad) and $20 \mu \mathrm{g}$ of protein (diluted in $2 \times$ Laemmli buffer with $5 \% \beta$-mercaptoethanol and boiled for $5 \mathrm{~min}$ ) was used for SDS/PAGE (10\% precast gel; Lonza). The proteins were transferred to polyvinylidene fluoride membranes (Bio-Rad) and blocked in 5\% nonfat milk before probing. Each step was performed in Tris-buffered saline with $0.1 \%$ Tween 20 . In short, the membranes were incubated with an affinity-purified rabbit anti-mouse Panx1 antibody (CT-395; $0.2 \mu \mathrm{g} / \mathrm{ml}$; Penuela et al., 2009; Bargiotas et al., 2011) for $12 \mathrm{~h}$ at $4^{\circ} \mathrm{C}$, washed, incubated with goat-anti-rabbit IgG antibody conjugated with HRP $(\sim 0.2 \mu \mathrm{g} / \mathrm{ml})$ for $1 \mathrm{~h}$, washed, and visualized on a molecular Imager (VersaDoc MP 5000; Bio-Rad) using enhanced chemiluminescence. Next, the membranes were reprobed with a goat-antimouse GAPDH antibody $(0.5 \mu \mathrm{g} / \mathrm{ml})$ and a donkey-anti-goat IgG antibody conjugated with HRP $(0.2 \mu \mathrm{g} / \mathrm{ml})$ and re-imaged.

Chemicals. For drugs that were dissolved as stock solutions $(1000 \times)$ the solvents are indicated in parentheses with the exception of probenecid, which was dissolved in $1 \mathrm{M} \mathrm{NaOH}$ and added directly to ACSF ( $\mathrm{pH}$ corrected to 7.35). Abcam supplied CNQX disodium salt (DMSO), APV D isomer $\left(\mathrm{H}_{2} \mathrm{O}\right)$, and tetrodotoxin (TTX) $\left(\mathrm{H}_{2} \mathrm{O}\right)$; GE Healthcare Bioscience supplied enhanced chemiluminescence; Bio-Rad supplied $\beta$-mercaptoethanol; Cal- biochem supplied FluorSave reagent; EMD supplied D- glucose and $\mathrm{NaHCO}_{3}$; FD NeuroTechnologies supplied PFA; Fisher Scientific supplied $\mathrm{CaCl}_{2}, \mathrm{DMSO}$, glycine, $\mathrm{NaH}_{2} \mathrm{PO}_{4}, \mathrm{KCl}$, and $\mathrm{MgCl} 2$; GE Healthcare supplied chemiluminescence and goat-anti-rabbit IgG antibody conjugated with HRP; Life Technologies supplied the Alexa 594-conjugated antibody against rabbit IgG, Alexa 488 hydrazide-sodium salt, and Texas Red; Oxoid supplied PBS (tablets); Pfizer supplied medetomidine; Research Biochemicals International supplied reactive blue $2\left(\mathrm{RB} 2 ; \mathrm{dH}_{2} \mathrm{O}\right)$; Sandoz supplied fentanyl and midazolam; Santa Cruz Biotechnology supplied antibody against GAPDH and donkey-anti-goat IgG antibody conjugated HRP; Sigma supplied $2 \times$ Laemmli buffer, ATP disodium salt hydrate $\left(\mathrm{H}_{2} \mathrm{O}\right)$, carboxy-2-phenyl-4, 4, 5, 5-tetramethylimidazoline-1-oxyl-3-oxide (PTIO); CBX disodium salt $\left(\mathrm{H}_{2} \mathrm{O}\right)$, halothane, HEPES, $\mathrm{NaCl}, \mathrm{Na}_{2}$ creatine $\mathrm{PO}_{4}, \mathrm{NMDA}\left(\mathrm{H}_{2} \mathrm{O}\right)$, $\mathrm{N}$-methyl-D-glucamine, potassium ATP, potassium gluconate, potassium EGTA, probenecid ( $1 \mathrm{M} \mathrm{NaOH})$, sodium GTP, sodium L-ascorbate, sodium pyruvate, Triton X-100, and Tween 20; Tocris Bioscience supplied: ARL, KN-62, L-NAME hydrochloride, MK-801, and pyridoxalphosphate-6azophenyl-2' $4^{\prime}$-disulfonic acid tetrasodium salt (PPADS) tetrasodium salt; Wako supplied the antibody against Ibal. The antibody against mouse Panx1 was a kind gift from Dr. Dale W. Laird (Western University, London, Ontario, Canada). The antibody against mouse P2Y12 was a kind gift from Dr. David Julius (University of California San Francisco, San Francisco, CA).

\section{Results}

Characteristics of ATP-induced microglial process outgrowth in slices and in vivo

We first established the validity of ATP responses in acutely prepared mouse brain slices. Bath application of ATP $(500 \mu \mathrm{M})$ consistently induced dynamic morphological changes of microglial cells, which we refer to as microglial process outgrowth (Fig. $1 A-C)$. This outgrowth was characterized by extension of existing processes, sprouting of new branches extending away from the soma, and formation of bulbous tips (growth cone-like structures at the leading edge of extending processes and branches). Importantly, every microglial cell (in control conditions) immediately responded to ATP and process outgrowth persisted as long as ATP was applied. The process outgrowth was completely reversible as microglia would return to their initial morphology within a few minutes upon removal of ATP. Furthermore, the process outgrowth could be repeated with additional ATP applications. 
A1

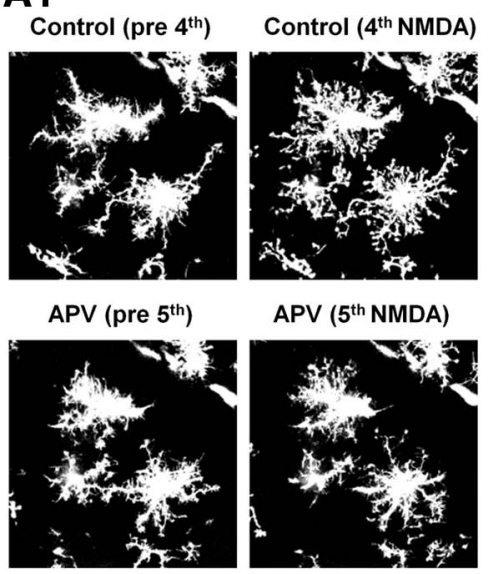

B1

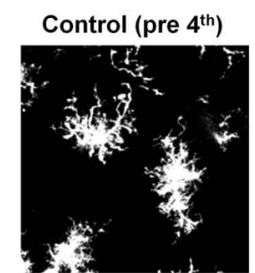

Control (4 ${ }^{\text {th }}$ NMDA)

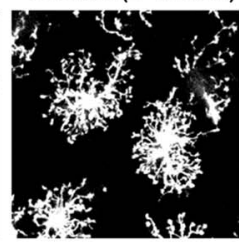

TTX + CNQX (pre $\left.5^{\text {th }}\right)$

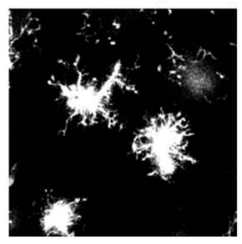

C1

Control (pre $4^{\text {th }}$ )

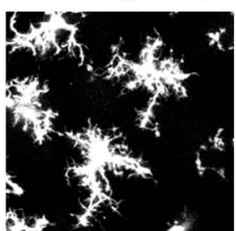

RB2 (pre $\left.5^{\text {th }}\right)$

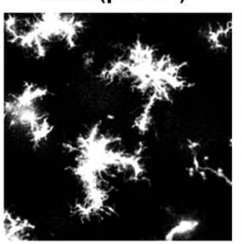

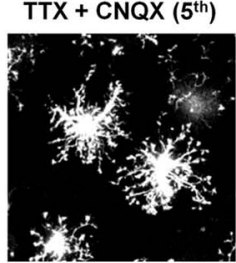

Control ( $4^{\text {th }}$ NMDA)

A2

Area

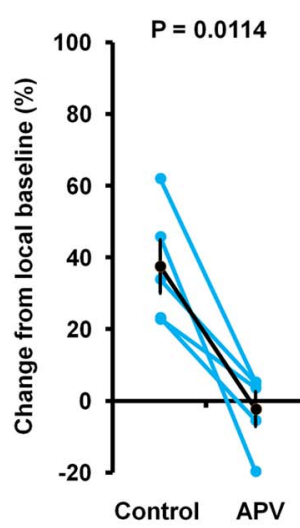

B2

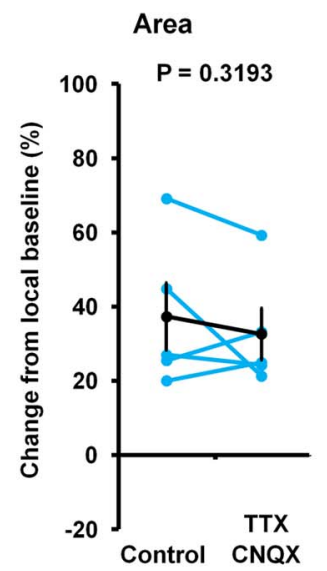

C2

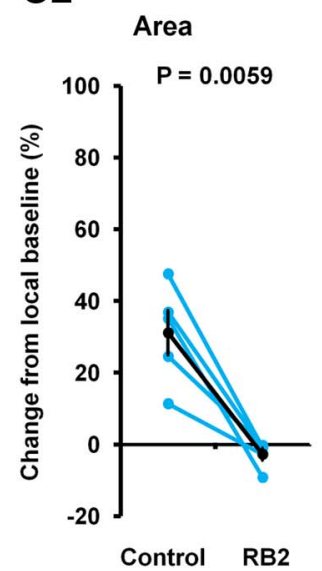

Perimeter

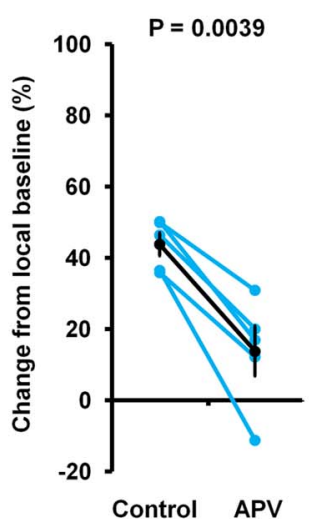

Perimeter

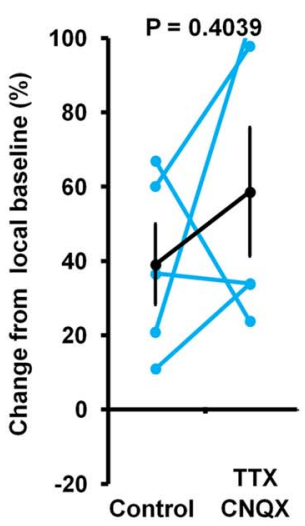

Perimeter

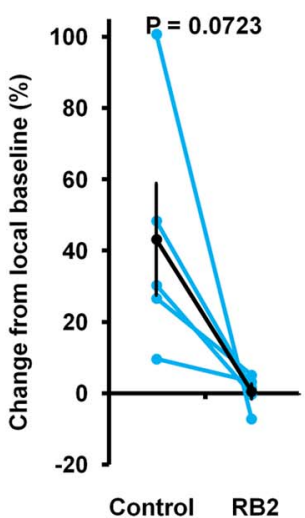

\# of Branch Points

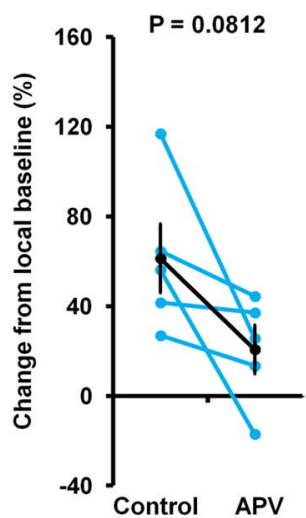

\# of Branch Points

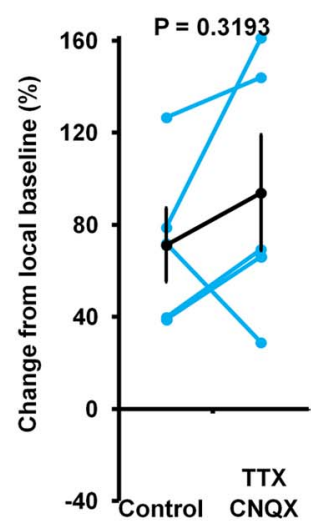

\# of Branch Points

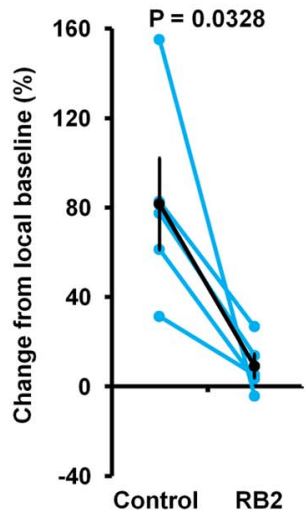

Figure 5. NMDA-triggered release of ATP is mediated by NMDA receptors and does not require action potentials or AMPA and kainate receptor stimulation. $A-C$, Multiple bath applications of NMDA using the paradigm presented in Figure 2 was performed with different pharmacological interventions initiated 25 min before the fifth NMDA application and continued throughout the experiment. A1-C1, Demonstration of microglial morphology shown at different time points (similar to Fig. 2, C-f). Local baselines are referred to as Pre NMDA. Scale bar, $20 \mu \mathrm{m}$. A1, Application of the NMDA receptor antagonist APV (100 $\mu$ M) abolished the outgrowth APV (5th NMDA) compared with APV (pre 5th) versus Control (4th NMDA) compared with Control (pre 4th). B1, Microglial process outgrowth still occurred independently of action potentials, blocked by TTX $(1 \mu \mathrm{M})$, and AMPA and kainate receptor stimulation, blocked by CNQX (50 $\mu \mathrm{M})$. C1, Application of the purinergic antagonist RB2 $(200 \mu \mathrm{M})$ completely abolished microglial process outgrowth. A2-C2, Graphic depiction of changes from the local baseline following the fourth NMDA application Control and the fifth NMDA application in the presence of the indicated pharmacological agents, determined as illustrated in Figure 2. Each data point is represented with a blue dot and data points from the same experiments are connected with blue lines. The mean \pm SEM is illustrated in black. A paired $t$ test was used to compare the two groups $(n=5)$.

To confirm that the characteristics of this ATP-induced microglial process outgrowth also occurred in vivo, ATP (10 mM) was topically applied to the intact cortex and a similar pattern of microglial process outgrowth was observed in microglia in vivo (Fig. $1 D$ ).
Characteristics of microglial process outgrowth triggered by NMDA

We observed that bath application of NMDA triggered a transient microglial process outgrowth that was similar to that induced by 
A1

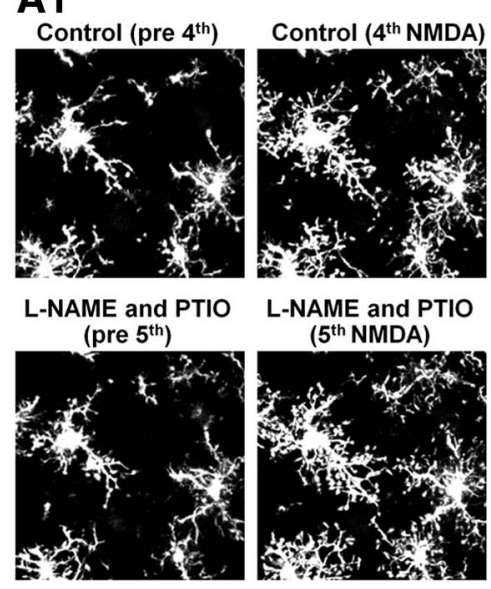

B1
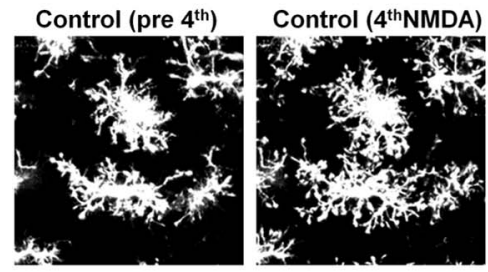

PPADS and KN-62 PPADS and KN-62 (pre $\left.5^{\text {th }}\right)$

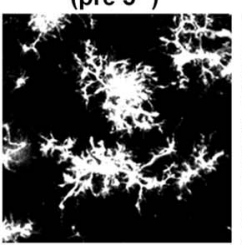
$\left(5^{\text {th }}\right.$ NMDA)

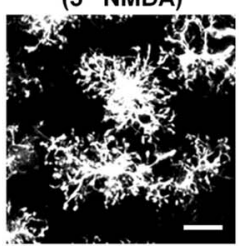

A2

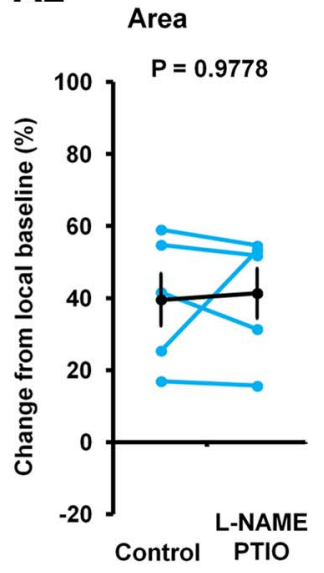

B2

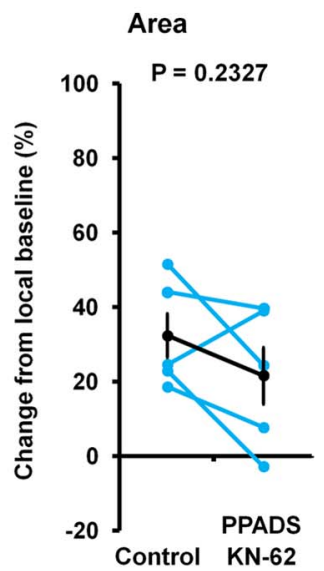

Perimeter

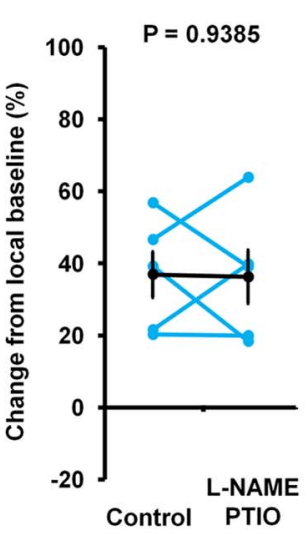

Perimeter

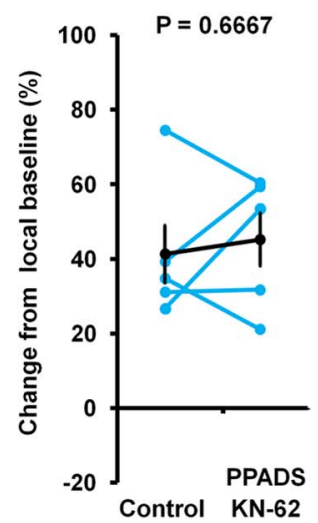

\# of Branch Points

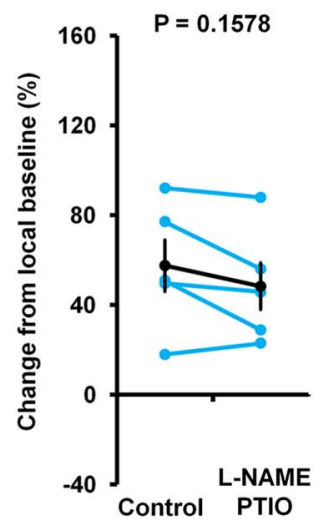

Figure 6. NMDA-triggered microglial process outgrowth does not depend on NO or ATP-mediated ATP release. $A, B$, Multiple bath applications of NMDA using the paradigm presented in Figure 2 was performed with different pharmacological interventions before the fifth NMDA application as described in Figure 5.A1-B1, Demonstration of microglial morphology shown at different time points. Local baselines are referred to as Pre NMDA. Scale bar, $20 \mu \mathrm{m}$. A1, Application of the NO-synthase blocker L-NG-nitroarginine methyl ester (L-NAME) (1 mM) together with the N0 scavenger, PTIO $(200 \mu \mathrm{M})$, had no effect on NMDA-triggered process outgrowth L-NAME and PTIO (5th NMDA) compared with L-NAME and PTIO (pre 5th) versus Control (4th NMDA) compared with Control (pre 4th). B1, Application of the P2Y1 blocker PPADS (200 $\mu \mathrm{m}$ ) together with the P2X7 blocker, KN-62 (15 $\mu \mathrm{M})$, had no effect on NMDA-triggered process outgrowth PPADS and KN-62 (5th NMDA) compared with PPADS and KN-62 (pre 5th) versus Control (4th NMDA) compared with Control (pre 4th). A2-B2, Graphic depiction of changes from the local baseline following the fourth NMDA application Control and the fifth NMDA application in the presence of the indicated pharmacological agents, determined as illustrated in Figure 2. Each data point is represented with a blue dot and data points from the same experiments are connected with blue lines. The mean \pm SEM is illustrated in black. A paired $t$ test was used to compare the two groups $(n=5)$.

ATP. The dynamics in microglial morphology in response to five 1 min bath applications of NMDA are illustrated in Figure 2, Movie 1. Transient exposure to NMDA triggered a reversible extension of existing processes, sprouting of new branches away from the soma, and formation of bulbous tips (Fig. 2B) and was quantified (area, perimeter, and number of branch points) as shown in Figure 2, $C$ and $D$. We observed that the microglial response to NMDA was variable during the first three applications whereas subsequent applications were consistently stable (Fig. 2D), hence we established a paradigm with three initial NMDA applications separated by $20 \mathrm{~min}$ intervals followed by $40 \mathrm{~min}$ intervals before NMDA applications 4 and 5 . Figure $2 D$ shows that the process outgrowth following the fourth application of NMDA compared with the first was significantly different with respect to the local baseline values obtained 5 min before the respective NMDA application. Importantly, comparisons of process outgrowth following the fourth and the fifth NMDA applications were not significantly different. This allowed us to test the effect of various blockers on the fifth application. We thus could compare the outgrowth triggered by the fourth NMDA application to the outgrowth triggered by the fifth NMDA application in the presence of various blockers. The longer intervals were introduced to allow for the outgrowth to peak (within $15 \mathrm{~min}$ ) and then sufficient time for introduction of pharmacological agents $(25 \mathrm{~min}$ ) before the fifth NMDA application.

\section{Comparison of microglia outgrowth triggered by NMDA} versus ATP

We examined the difference between the patterns of process outgrowth triggered by NMDA versus ATP application on the same cells. This was investigated by acquiring $z$-stacks of images before and after NMDA and ATP application to create $3 \mathrm{D}$ reconstructions of microglia when process outgrowth was triggered by either stimulus. The microglial process outgrowth induced by NMDA was nonpolarized resulting in a spatially uniform distribution of bulbous tips and a quantified polarization of $\sim 50 \%$ (Fig. $3 C 1, D)$. In contrast, process outgrowth induced by bath application of ATP was strikingly polarized with a greater extension of processes directed toward the surface of the brain slice where the ATP was diffusing into the tissue (Fig. 3C2,D). This is consistent with the hypothesis that ATP generates polarized outgrowth because a gradient is generated as the ATP diffuses into the brain slice. In contrast, the nonpolarized process outgrowth 
A1

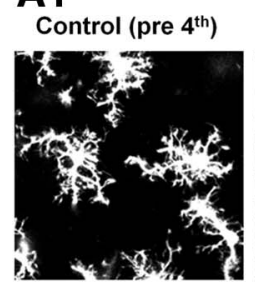

ARL (pre $5^{\text {th }}$ )

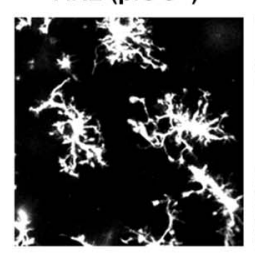

B1

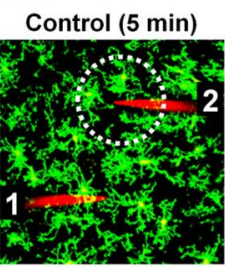

$50 \mu \mathrm{M}$ ARL(5 min)

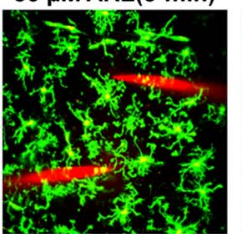

Control ( $4^{\text {th }}$ NMDA)

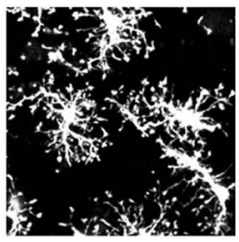

ARL (5 ${ }^{\text {th }}$ NMDA)

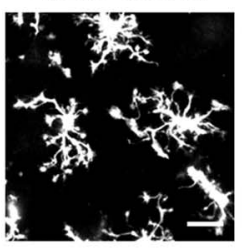

Control (45 min)

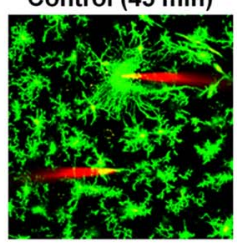

$50 \mu \mathrm{M}$ ARL(45 min)

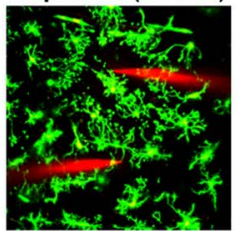

A2

Area

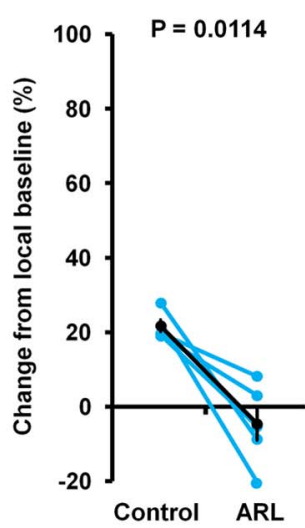

B2

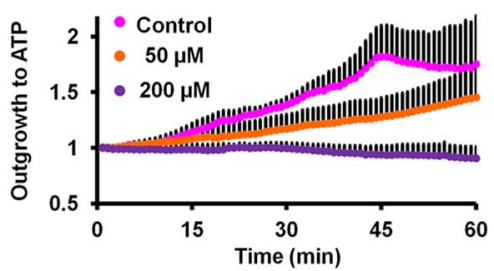

$200 \mu \mathrm{M}$ ARL(5 min) $200 \mu \mathrm{M}$ ARL(45 min)

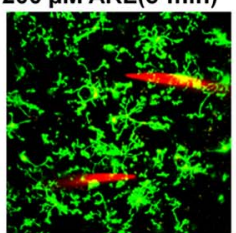

Perimeter

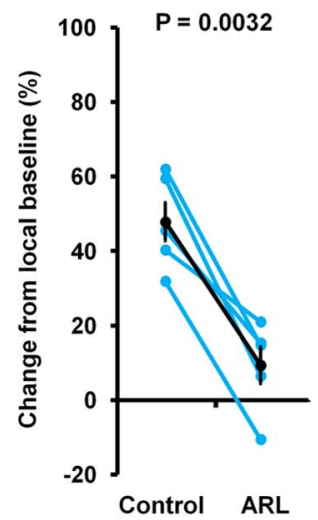

\# of Branch Points

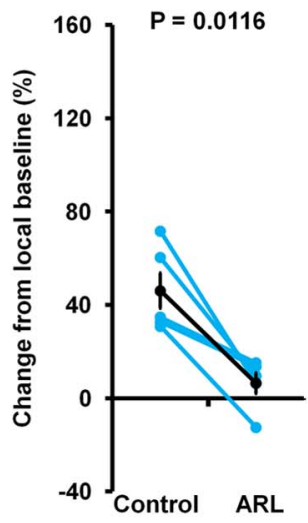

B3

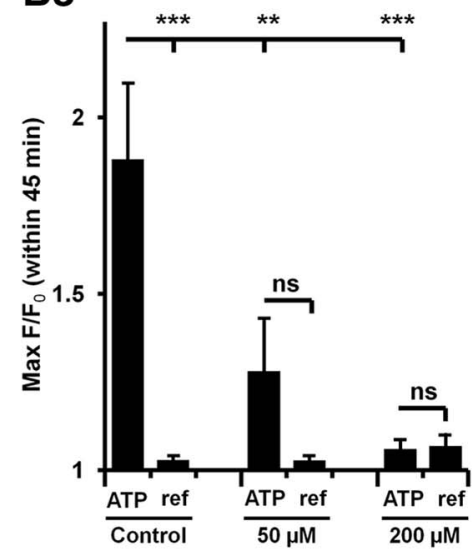

Figure 7. NMDA-triggered microglial process outgrowth was blocked by inhibiting hydrolysis of ATP. A1, A2, Multiple bath applications of NMDA using the paradigm presented in Figure 2 was performed with application of the ectonucleotidase inhibitor, ARL (50 $\mu \mathrm{m}$ ) before the fifth NMDA application. A1, Demonstration of microglial morphology shown at different time points. Local baselines are referred to as Pre NMDA. Scale bar, $20 \mu \mathrm{m}$. A2, Application of ARL abolished NMDA-triggered process outgrowth ARL (5th NMDA) compared with ARL (pre 5th) versus Control (4th NMDA) compared with Control (pre 4th). The mean \pm SEM is illustrated in black. A paired $t$ test was used to compare the two groups $(n=5)$. $B$, Local application of ATP was used to validate the effect of ARL. Two electrodes was placed $100 \mu \mathrm{m}$ apart. One electrode (1) contained ACSF and served as a reference while the other electrode (2) contained ACSF with $4 \mathrm{~mm}$ ATP. Note the processes surrounding the tip at Control (45 min). B2, Graphic depiction of outgrowth toward the ATP-containing electrodes (measured as $F / F_{0}$ ). Note the peak after 45 in control when all the processes have reached the tip of the electrode. $B 3$, Graphic depiction of $\max F / F_{0}$ within the first 45 min demonstrating a significant outgrowth toward the ATP-containing electrode compared with the reference electrode (ref). Fifty micrometer ARL significantly reduced the outgrowth to ATP compared with the outgrowth observed in control $200 \mu \mathrm{m}$ ALR that completely blocked the directed outgrowth. One-way ANOVA with Bonferroni's multiple-comparison post-test was used for statistical comparison six groups $(n=3)$; ${ }^{* *} p<0.01,{ }^{* * *} p<0.001$.

in NMDA is consistent with the release of chemoattractant agents from neurons throughout the brain slice as a result of NMDAR activation. Additionally, we acquired images immediately after terminating the ATP application. We observed that the bulbous tips withdraw before the retraction of the extended processes when the ATP application is terminated.

Outgrowth occurred independently of CX3CR1 stimulation The fractalkine receptor on microglia is known to respond to neuronal fractalkine and is potentially a candidate in directing or triggering microglia process outgrowth (Liang et al., 2009). The expression of EGFP in microglia in our transgenic mice is driven by CX3CR1. To investigate whether the outgrowth would be altered by the presence or absence of the CX3CR1 fractalkine receptor, slices from both CX3CR $1^{-/-}$and CX3CR $1^{-/+}$mice were subjected to the multiple NMDA applications paradigm (Fig. 4). Similar outgrowth occurred in slices from both transgenic mice and no significant differences were observed for any of our three parameters. Thus, microglia process outgrowth did not require the fracktalkine receptor. CX3CR1 $1^{\text {EGFP/EGFP }}$ mice, which have optimal expression of EGFP and provide the best signal-to-noise ratio while imaging dynamic processes, were used for subsequent experiments.

\section{NMDA-triggered ATP release is selective to}

NMDAR stimulation

We next investigated whether ATP was released as a result of NMDA receptor activation or if NMDA directly activated microglial cells. As described above, when NMDA was briefly applied at five different times there was no significant difference between the outgrowth following the fourth and the fifth NMDA applications. Therefore, we applied pharmacological agents 25 min before the fifth NMDA application and measured microglia process outgrowth to compare with the extent of outgrowth from the fourth NMDA application, which is referred to as control (Fig. 5). We determined, as expected, that the NMDA-triggered outgrowth was due to NMDAR activation because process outgrowth was abolished by the NMDAR antagonist APV (Fig. 5A). Outgrowth still occurred in TTX to block action potentials and CNQX, at a concentration to block both AMPA and kainate receptors, (Fig. 5B). Several studies have shown that ATP is a key trigger for microglial process outgrowth (Davalos et al., 2005; Haynes et al., 2006). We tested 
A1
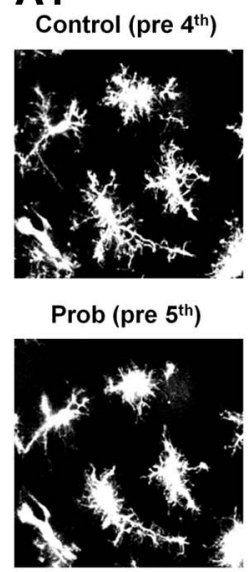

B1
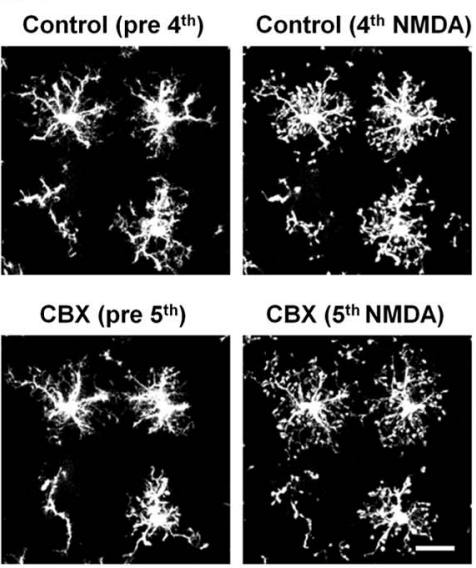

C

Summary (\# of Branch Points)

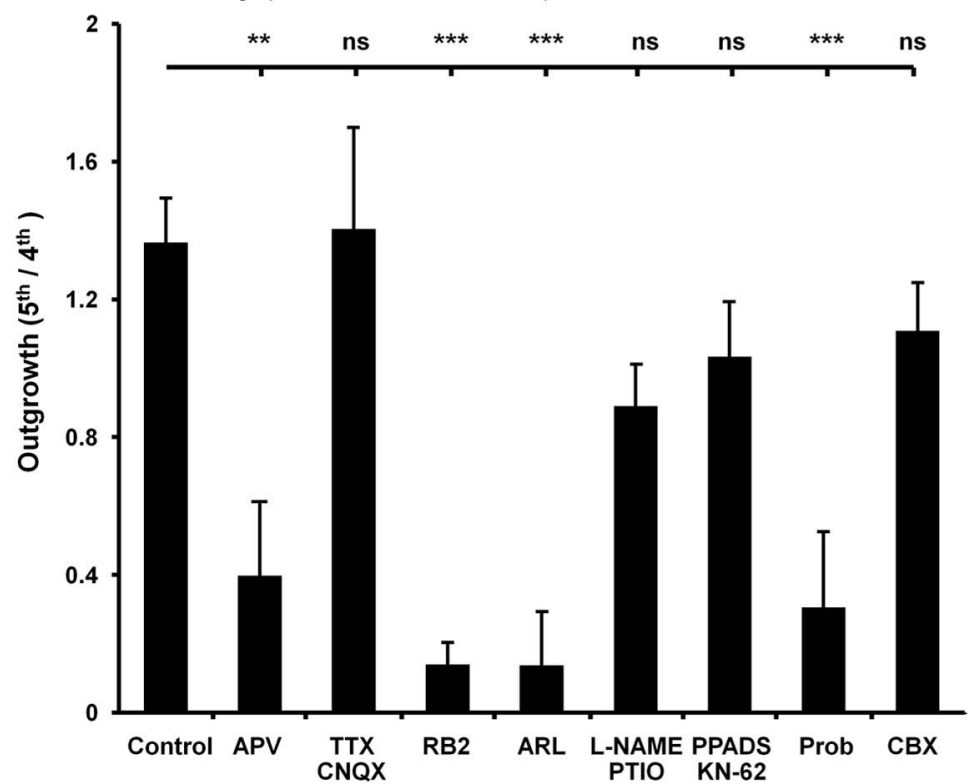

A2

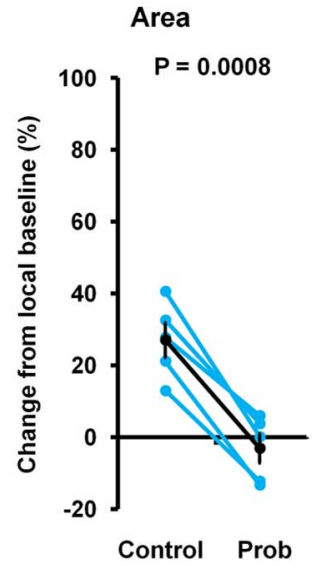

B2
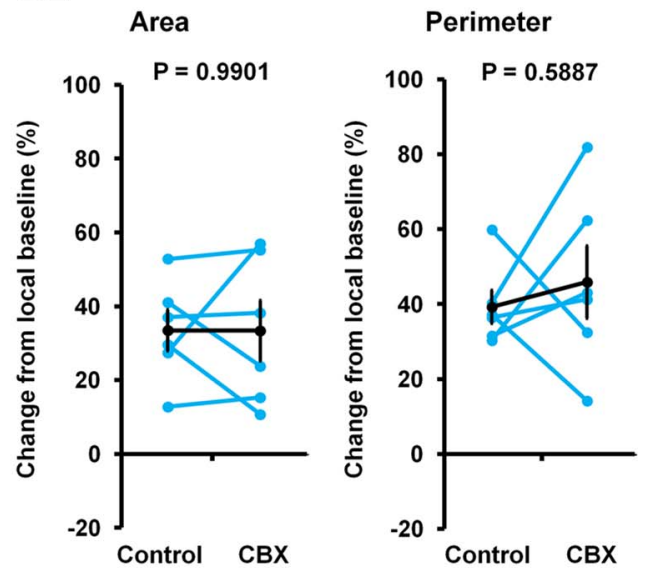

D

\# of Branch Points
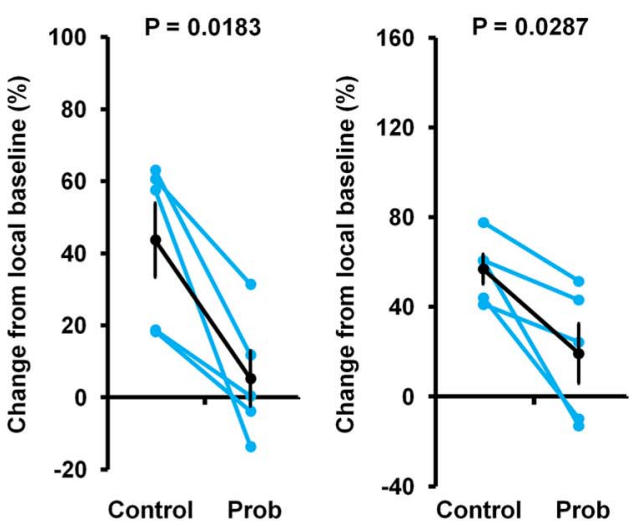

\# of Branch Points

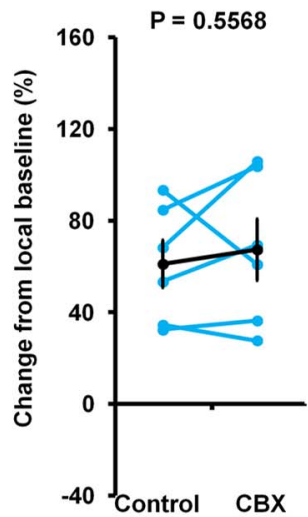

E

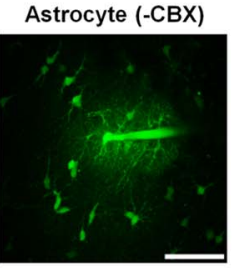

Astrocyte in CBX

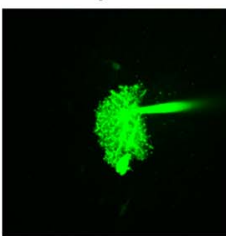

Merged with SR101

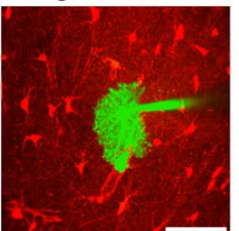

APV and Prob

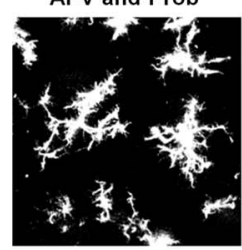

ATP in APV and Prob

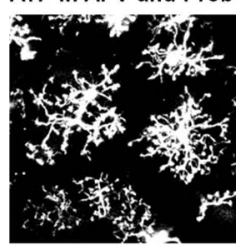

ATP in RB2

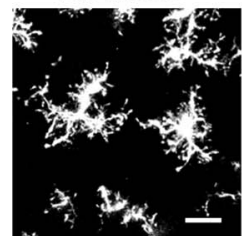

Figure 8. NMD- triggered ATP release is sensitive to probenecid (Prob) but is not blocked by the Panx1 inhibitor CBX. $A, B$, Multiple bath applications of NMDA using the paradigm presented in Figure 2 were performed with different pharmacological interventions before the fifth NMDA application as described in Figure $5 . \mathbf{A 1}, \mathbf{B 1}$, Demonstration of microglial morphology shown at different time points. Local baselines are referred to as Pre NMDA. Scale bar, $20 \mu \mathrm{m}$. A1, Application of Prob (2 mM) abolished the outgrowth. Prob (5th NMDA) compared with Prob (pre $5 f$ th) versus Control (4th NMDA) compared with Control (pre 4th). B1, Microglial process outgrowth was not blocked by the potent Panx1 inhibitor, CBX (100 $\mu \mathrm{m})$. A2, B2, Graphic depiction of changes from the local baseline following the fourth NMDA application Control and the fifth NMDA application in the presence of either Prob or CBX, determined as illustrated in Figure 2. Each data point is represented with a blue dot and data points from the same experiments are connected with blue lines. The mean \pm SEM is illustrated in black. A paired $t$ test was used to compare the two groups; $n=5$ for $\mathbf{A} 2$ and $n=6$ for B2.C, Graphic summary of the increase of number of branch points following NMDA-triggered ATP release in the presence of the different pharmacological agents (Figure legend continues.) 
A

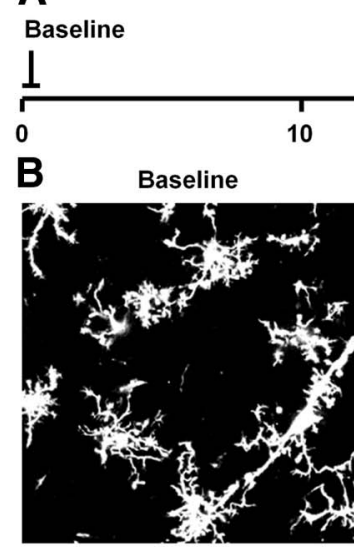

Lesion
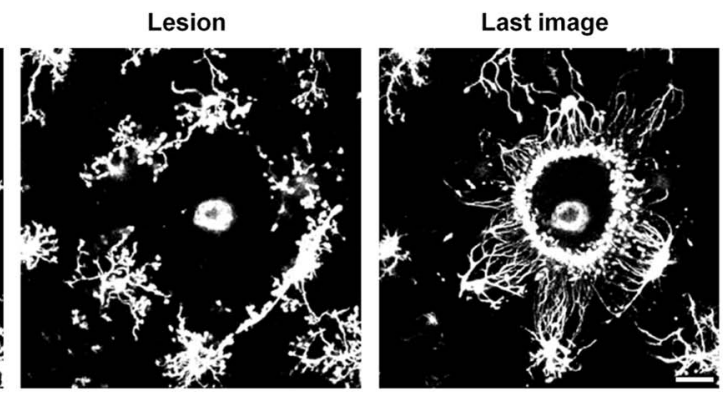

$40 \mathrm{~min}$

C2

anti-P2Y12

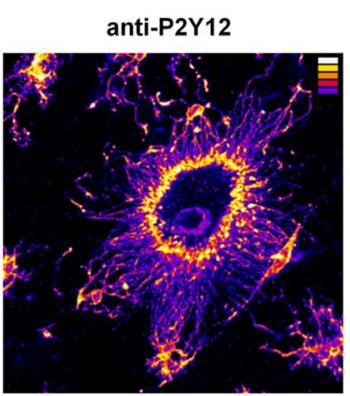

D Control, anti-P2Y12

C1 Post fixation, EGFP
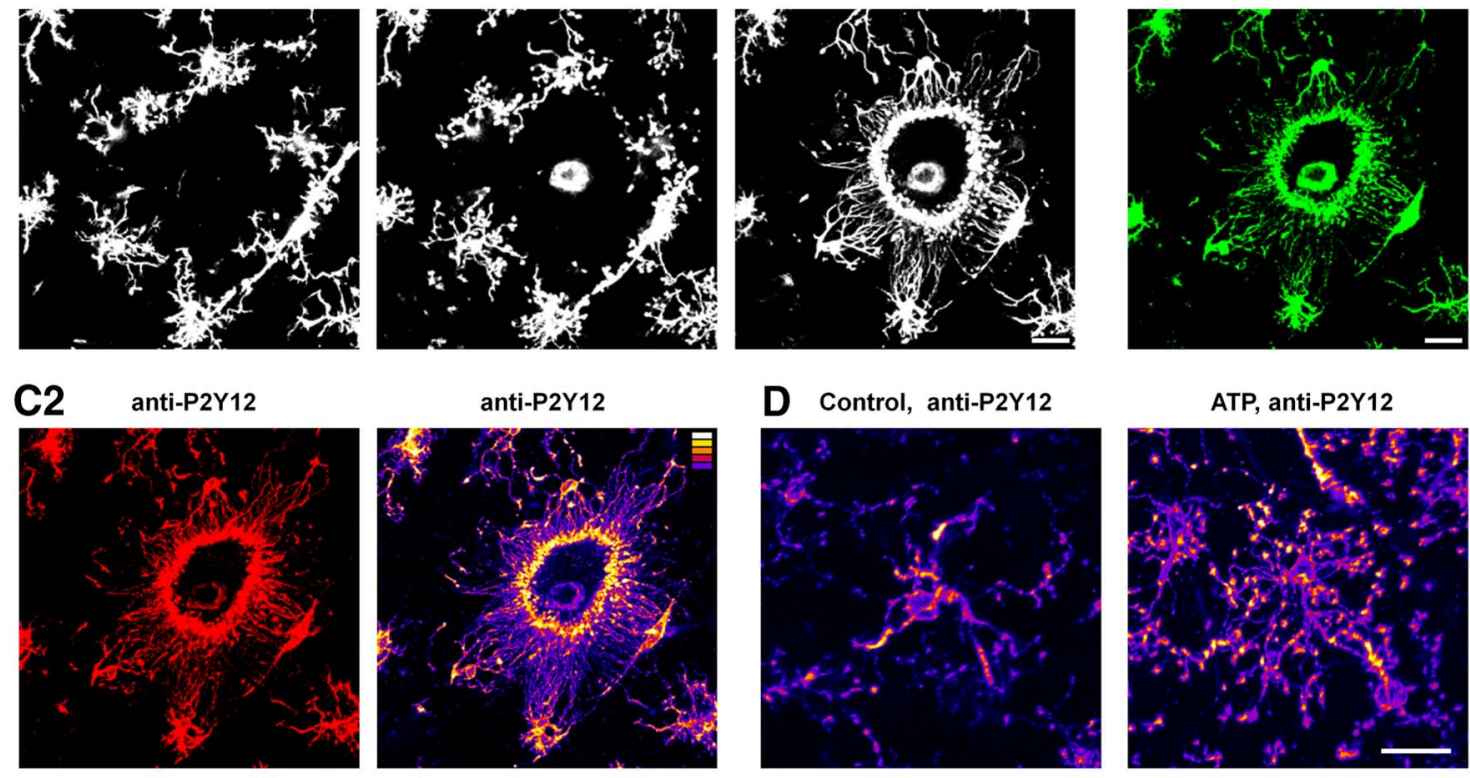

E Control, anti-lba1

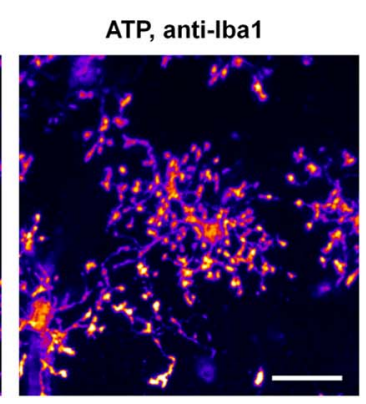

$\mathbf{F}$

Control, EGFP
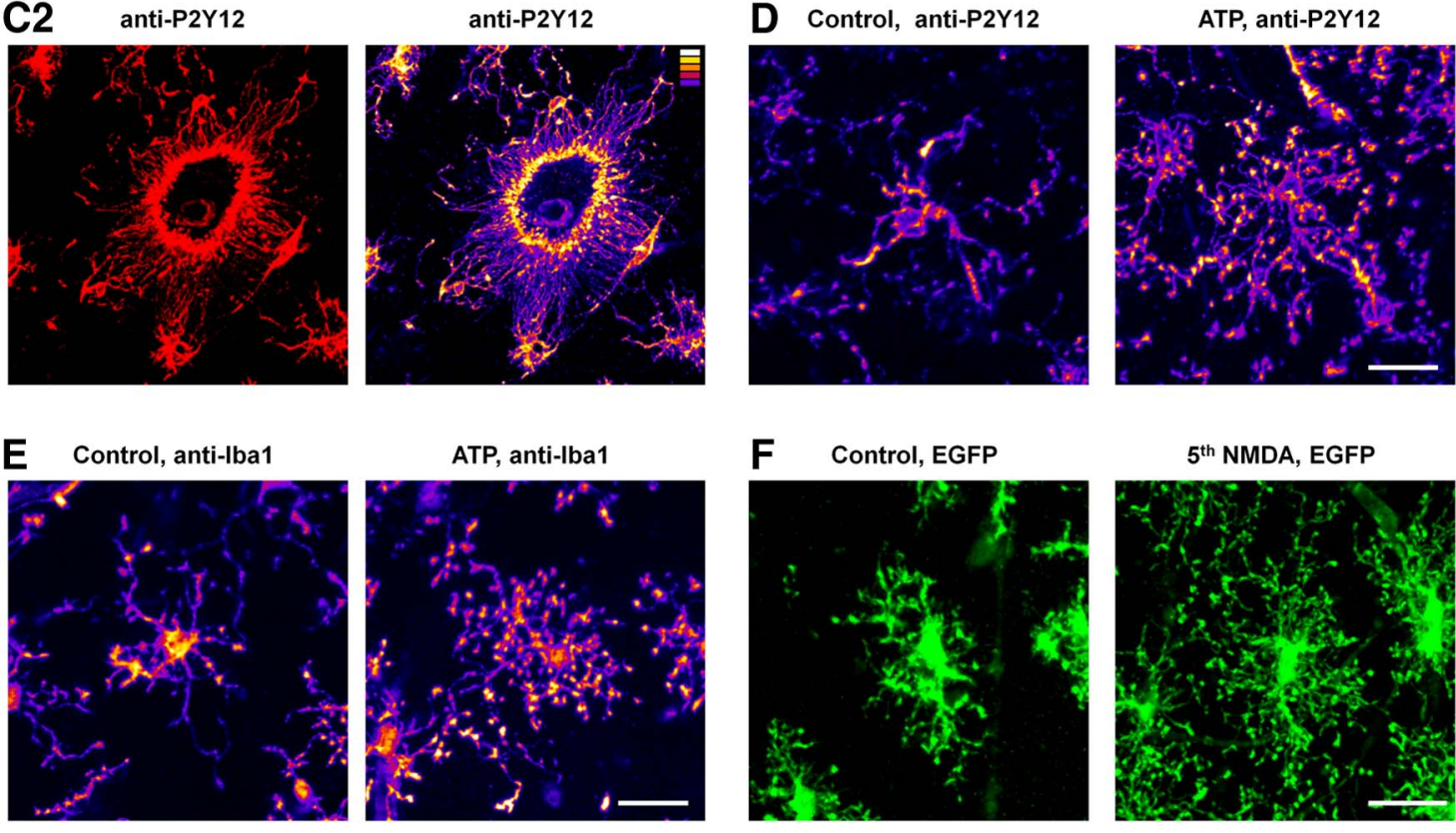

Fix

Fixation

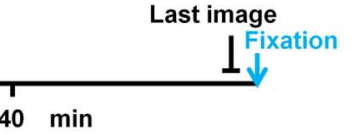

Figure 9. SNAPSHOT allowed for morphological and immunohistochemical analysis of dynamic processes preserved at specific time points. $A$, Time line for image acquisition, formation of a lesion (indicated with a red arrow), and the time of fixation (indicated with a blue arrow). $\boldsymbol{B}$, Example frames from real-time imaging of EGFP ${ }^{+}$ve microglia over $48 \mathrm{~min}$. The bright circular region in the Lesion image is the lesion area that was induced by exposure of high laser power illumination restricted to this area. Note that the Last image was acquired $<1 \mathrm{~min}$ before fixation. Scale bar, $50 \mu \mathrm{m}$. C1, C2, Morphology of the brain slice that was fixed 30 min after lesioning and immunolabeled using the SNAPSHOT method. C1, Microglial process outgrowth toward the lesion was preserved and could be visualized by imaging of EGFP. C2, Illustration of P2Y12 immunolabeling and pseudocoloring of the nonsaturated labeling intensity [intensity scale for 8-bit image (top right corner); 0 (black), 50, 100, 150, 200, 255 (white)]. The SNAPSHOT protocol allowed us to detect that high levels of P2Y12 receptors were located at the bulbous tips. D, A similar pattern of preferential distribution of P2Y12 immunolabeling to the growing tips was reproduced when SNAPSHOT was applied to preserve the microglial process outgrowth triggered by ATP application (15 min). Note the increased intensity of labeling at the bulbous tips compared with the processes in control conditions. Scale bar, $20 \mu \mathrm{m}$. E, A similar pattern of preferential localization at the bulbous tips was also observed with Iba1 immunolabeling of ATP-induced process outgrowth. Scale bar, $20 \mu \mathrm{m}$. $\boldsymbol{F}$, Fixation of brain slices subjected to five NMDA applications demonstrated that NMDA-triggered microglial process outgrowth (fixed $8 \mathrm{~min}$ after the fifth NMDA application) can be preserved using the SNAPSHOT method. Scale bar, $20 \mu \mathrm{m}$.

\footnotetext{
$\leftarrow$

(Figure legend continued.) shown in Figures $5 A-C, 6, A$ and $B, 7 A$, and $8, A$ and $B$. The increase in number of branch points is presented as the change from local baseline following the fifth NMDA application/the change from local baseline following the fourth NMDA application. The control group consists of the experiments depicted in Figures 2 and $4 A(n=14)$. One-way ANOVA with Bonferroni's multiple-comparison post-test was used for statistical comparison of the nine groups; ${ }^{* *} p<0.01$ and ${ }^{* * *} p<0.001 . \boldsymbol{D}, \boldsymbol{E}$, Demonstration of control experiments performed for (BX, APV, Prob, and RB2, respectively. D, In control, (absence of (BX) whole-cell patch clamping of a single astrocyte with a fluorescent dye (Alexa 488, observed in green) inside the patch pipette allowed for dye diffusion through the gap junctions to surrounding astrocytes. However, in the presence of CBX the dye was restricted within the patched astrocyte and thus not observed in the surrounding astrocytes (loaded with sulforhodamine 101, SR101, and observed in red). Scale bar, $50 \mu \mathrm{m}$. $E$, ATP-induced outgrowth still occurred in the presence of both APV and Prob but was blocked by RB2 (same concentration as used with NMDA applications). Scale bar, $20 \mu \mathrm{m}$.
}

whether ATP release underlies the microglial response to NMDA by applying a broad-spectrum ATP receptor antagonist, RB2 (Fig. 5C). RB2 is a potent competitive antagonist for P2Y12 (Hoffmann et al., 2008) and has previously been successfully used to block microglial process extension toward laser-induced lesions (Davalos et al., 2005). We found that RB2 completely blocked NMDA-triggered outgrowth indicating that microglial process outgrowth is mediated by a secondary release of purinergic agonists downstream the action of NMDA.

NMDA-triggered microglial process outgrowth does not depend on nitric oxide or ATP-mediated ATP release Since neuronal NMDAR activation is well known to result in nitric oxide (NO) production (Christopherson et al., 1999; Sat- 


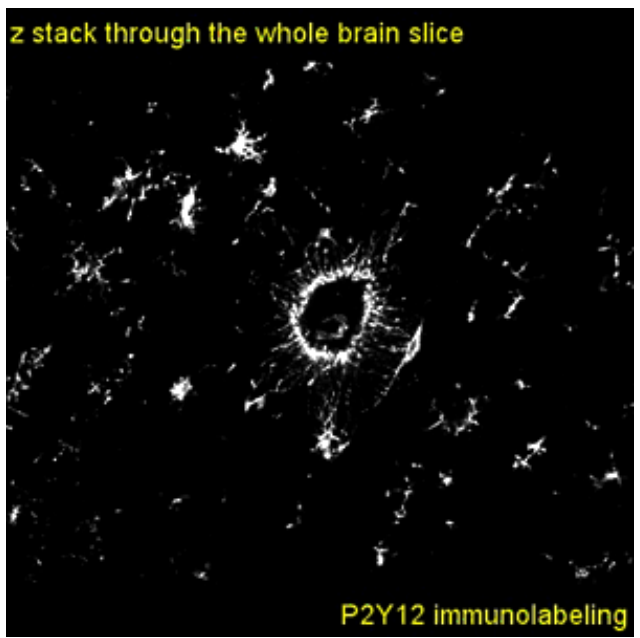

Movie 2. z-stack through a whole-brain slice immunolabeled for P2Y12.z-stack through the $300-\mu \mathrm{m}$-thick slice that has been fixed and immunolabeled using SNAPSHOT. The tissue was fixed 30 min after a lesion was induced (shown in Movie 9) and the purinergic receptor P2Y12 was immunolabeled and visualized throughout the slice ( $z=151$ images, stepping $2 \mu \mathrm{m}$ ). The depth below the surface is indicated in micrometers in the top right corner.

tler et al., 1999; d'Anglemont de Tassigny et al., 2007), and NO has previously been reported to be a modulator of acute microglial reactions in the spinal white matter (Dibaj et al., 2010), we examined whether NMDA-induced NO formation contributed to microglia process outgrowth in our assay. Application of the potent blocker of NO synthase L-NAME together with the NO scavenger, PTIO, did not block microglial process outgrowth (Fig. 6A), suggesting that the NMDA-induced microglia process outgrowth was independent of $\mathrm{NO}$ production. In addition, the possibility that NMDA-triggered outgrowth required amplification of ATP itself via P2Y1 or P2X7 receptors was tested. Astrocytic P2Y1 receptors, which are sensitive to broad-spectrum purinergic inhibitors such as RB2 and PPADS, and P2X7 receptors, which are inhibited by $\mathrm{KN}-62$, have been reported to mediate ATP-induced ATP release (Pascual et al., 2012; Baroja-Mazo et al., 2013). Since RB2 blocked the microglia outgrowth, presumably by blocking P2Y12 receptors, we applied PPADS (which does not block P2Y12) together with the selective P2X7 blocker KN-62 (Baraldi et al., 2003), both of which failed to block NMDA-induced microglia process outgrowth (Fig. $6 B$ ).

\section{NMDA-triggered microglial process outgrowth requires} ATP hydrolysis

Adenosine A3 receptor activation has also been reported to act synergistically with P2Y12 receptor stimulation to enhance microglia process outgrowth (Ohsawa et al., 2012). Thus we examined whether blocking the hydrolysis of ATP using the selective ectonucleotidase inhibitor ARL would alter the NMDA-triggered outgrowth (Fig. 7). ARL (50 $\mu \mathrm{M})$ abolished the NMDA-triggered microglial process outgrowth (Fig. $7 A$ ) thereby indicating that local gradients of ATP and its derivates $(\mathrm{ATP} \rightarrow \mathrm{ADP} \rightarrow \mathrm{AMP} \rightarrow$ adenosine) by hydrolysis of ATP are crucial for microglial process outgrowth. We validated this observation by blocking the directed outgrowth to local application of ATP with ARL. Fifty micrometers ARL significantly reduced the outgrowth to $4 \mathrm{mM}$ ATP and $200 \mu \mathrm{M}$ ALR completely blocked the directed outgrowth (Fig. 7B).

NMDA-triggered release of ATP occurred independently of Panxl but was sensitive to probenecid

We next examined whether the Panxl channel opening was responsible for the release of ATP that induced process outgrowth when NMDAR was stimulated. We examined the activation of process outgrowth in microglia using the repetitive NMDA perfusion protocol described above with pharmacological interventions $25 \mathrm{~min}$ before the fifth NMDA application (Fig. 8). The nonselective Panx1 channel blocker, probenecid (Silverman et al., 2008), completely blocked process outgrowth (Fig. 8A). In contrast, when we applied the potent blocker of Panxl channels, CBX (Thompson et al., 2006, 2008), there was no significant decrease in any of the measures of process outgrowth (Fig. $8 B$ ). We performed additional control experiments to show that ATPinduced outgrowth still occurred in the presence of probenecid but was indeed blocked by RB2 (applied at the same concentration and at the same duration as for the NMDA experiments; Fig. $8 D$ ). In addition, we ensured that CBX at this concentration effectively blocked dye flux through astrocytic gap junctions (Fig. $8 E$ ), which are less sensitive than Panx1 to CBX (Spray et al., 2006). Thus the concentration of CBX would also block ATP release that might occur via connexin hemichannels (Pearson et al., 2005; Torres et al., 2012). The control experiments clearly demonstrated that ATP-induced outgrowth still occurred in the presence of probenecid and that CBX completely blocked dye flux between astrocytes. Therefore based on the pharmacology the release mechanism does not appear to require Panx1 (or other connexin hemichannels) but is sensitive to probenecid.

SNAPSHOT preserved microglia morphology to demonstrate NMDA-triggered outgrowth and that P2Y12 and Iba1 were localized to growing bulbous tips

To gain novel insight into the location of the P2Y12 receptors during the morphological changes, we established a modified protocol for rapid and reliable fixation and immunolabeling of morphological changes in whole-brain slices (Fig. 9). Our fixation protocol (SNAPSHOT) provided excellent preservation of microglia morphology when examining $\mathrm{EGFP}^{+}$ve microglia highlighted by the preservation of the processes growing toward a lesion (Fig. 9B-C1). Using our immunolabeling protocol we observed labeling of P2Y12 throughout the $300-\mu \mathrm{m}$-thick slice (Movie 2). By acquiring nonsaturated images of the expression of the membrane proteins P2Y12 and Iba1, we demonstrated a preferential accumulation of these proteins at the bulbous tips during outgrowth (Fig. 9C2-E. Importantly, we also demonstrated that this fixation protocol can preserve NMDA-triggered process outgrowth (Fig. $9 F$ ) and thereby makes it an ideal tool for investigating the NMDA-triggered outgrowth in CX3CR $1^{+/+}$microglia that do not express EGFP.

\section{Microglial outgrowth still occurred in Panx1-deficient mice} In light of the discrepancies in the results obtained using pharmacological inhibitors of Panx1, we aimed to determine whether NMDA still induced microglia process outgrowth in brain slices from Panx $1^{-1-}$ mice (Fig. 10). Western blots confirmed complete absence of Panx1 protein in the Panx $1^{-/-}$mice at 6 weeks of age while the Panx1 protein was observed in strain-specific WT $(\mathrm{C} 57 \mathrm{BL} / 6)$ and at similar levels in the transgenic strain used for microglial time-lapse imaging $\left(\mathrm{CX}_{3} \mathrm{CR} 1^{\text {EGFP/EGFP }}, \mathrm{BALB} / \mathrm{C}\right)$ (Fig. $10 C)$. We therefore tested whether NMDA could cause process outgrowth in brain slices from Panx $1^{-1-}$ mice that were subjected to multiple NMDA applications. The slices were fixed 8 min after the fifth NMDA application using the protocol that we found to reliably preserve microglia morphology. Comparisons were made between brain slices treated with NMDA (10 slices from five animals) versus untreated brain slices that were perfused in tissue chambers for identical periods of time (five slices 
A

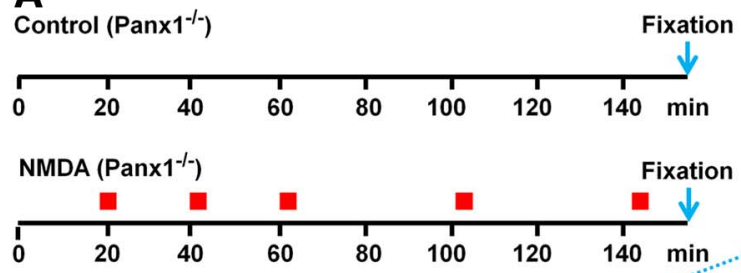

B

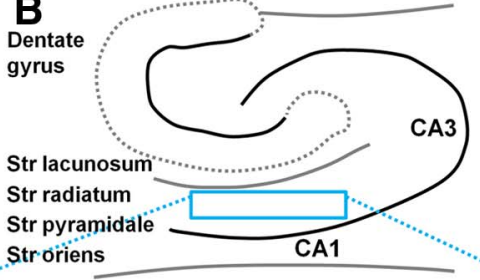

Stróriens

Control (Iba1 immunolabeled str radiatum in Pan $\times 1^{-/-}$mouse)
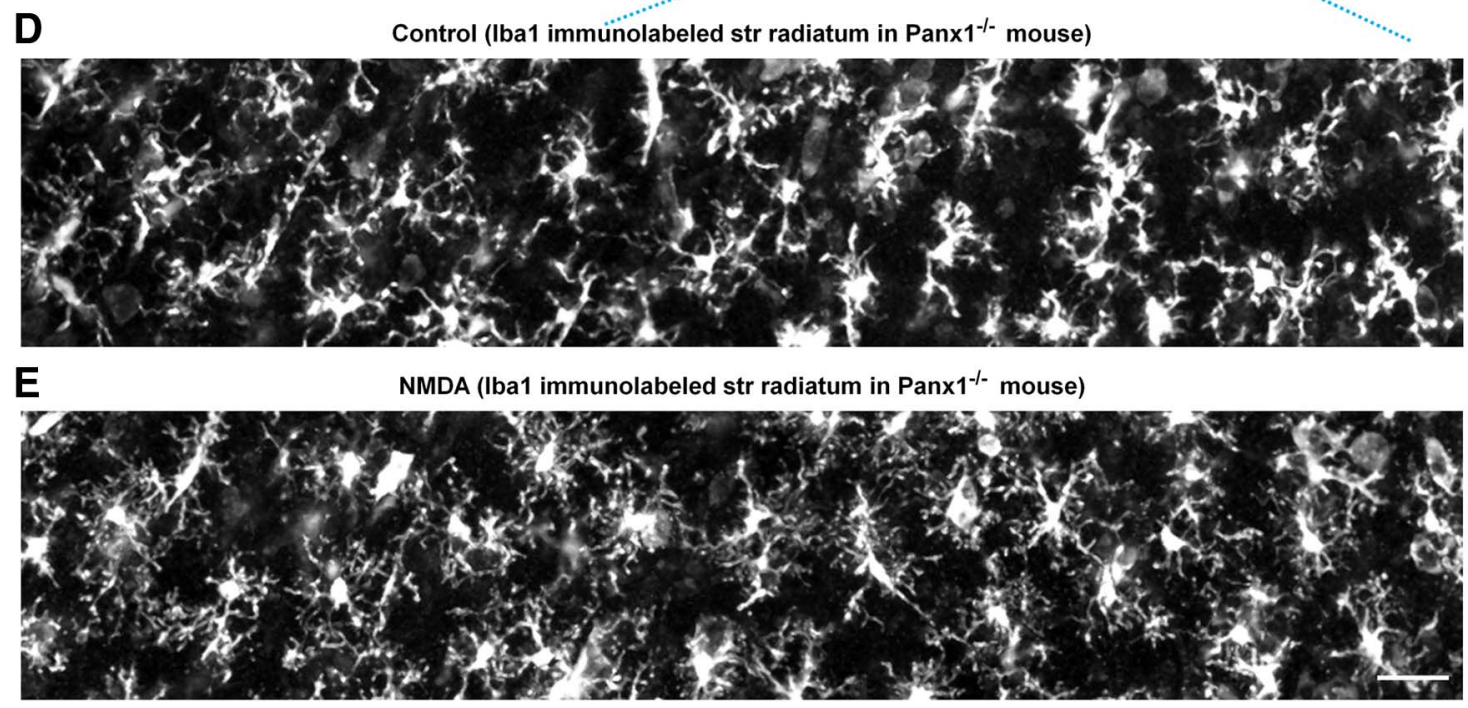

Figure 10. NMDA-triggered ATP release is independent of Panx1 expression. $\boldsymbol{A}$, Time line for NMDA applications (indicated with red markers) and time of fixation (indicated by blue arrows) compared with matched controls with no NMDA applications. $\boldsymbol{B}$, Schematic showing the portion of the hippocampal CA1 region that was analyzed for morphological changes of microglia. $\boldsymbol{C}$, Western blots of hippocampal brain slice homogenates obtained from Panx1-deficient mice (on C57BL/6 background; Panx1 ${ }^{-/-}$), C57BL6 wild-type mice (WT), and CX3CR1 ${ }^{\text {EGFP/EGFP }}$ mice (on BALB/C background; $\left(X 3 \mathrm{CR}^{-/-}\right.$) were stained with Panx1 antibodies (Panx1 expected size $48 \mathrm{kDa}$ ) and reprobed with antibodies against GAPDH (expected size $37 \mathrm{kDa}$ ). $\boldsymbol{D}, \boldsymbol{E}$, Using our protocol (SNAPSHOT) the microglial morphology at the time of fixation was preserved and visualized by lba1 immunolabeling. $\boldsymbol{D}$, Illustration of the microglia morphology in a horizontal cross section of the stratum (Str) radiatum in the CA1 in a control slice from a Panx $1^{-1-}$ mouse that was not subjected to NMDA applications. $E$, Illustration of the change in microglia morphology in a slice (from the same Panx $1^{-1-}$ mouse shown in $\left.\boldsymbol{D}\right)$ that was subjected to five NMDA applications, using the paradigm presented in $A$, and fixed 8 min after the fifth NMDA application. Scale bars: $50 \mu \mathrm{m}$.

from the same five animals). We used immunolabeling of Iba1, a specific microglia cell marker (Imai et al., 1996) to visualize microglia morphology. Extensive process outgrowth with bulbous tips was observed in microglia from Panx1 ${ }^{-/-}$mice following five NMDA applications. Microglia in untreated slices showed a characteristic ramified morphology (Fig. $10 D, E$ ). This result also confirms that outgrowth occurs in $\mathrm{CX} 3 \mathrm{CR} 1^{+/+}$mice and laserinduced phototoxicity does not play any role in the outgrowth observed in our paradigm. In addition the observation of outgrowth in microglia from NMDA application in Panx1 ${ }^{-/-}$confirms the pharmacological data that the process does not require ATP release from Panx1 channels.

Microglial process outgrowth triggered by selective NMDAR activation on a single neuron

To determine whether the initial trigger of microglial process outgrowth can be ascribed to activation of dendritic neuronal NMDAR (vs potential NMDAR expression on glial cells) we patch clamped CA1 pyramidal neurons using a strategy to selectively activate NMDAR on a single neuron. Experiments were performed in the presence of high extracellular $\mathrm{Mg}^{2+}(6 \mathrm{~mm})$ to block neuronal NMDAR at resting membrane potential. Additionally, TTX and CNQX (to block voltage-gated sodium channels and AMPA/kainate receptors, respectively) were applied to prevent spontaneous depolarization of other neurons (Fig. 11). Single patch-clamped neurons were depolarized to $0 \mathrm{mV}$, thereby removing the magnesium block and permitting activation of NMDAR on the clamped neuron while NMDAR on surrounding neurons were still blocked. In control experiments, neurons were kept hyperpolarized at $-70 \mathrm{mV}$ to maintain the $\mathrm{Mg}^{2+}$ block and prevent NMDAR activation or cells were patched and depolarized with MK-801 in the patch electrode to block open NMDA channels. Significant microglia outgrowth was observed only when the neuron was depolarized to allow NMDAR activation but not when the neuron was kept hyperpolarized or when the NMDAR open channel blocker, MK-801, was added to the internal solution (Fig. $11 B-E)$. To confirm that $6 \mathrm{~mm} \mathrm{Mg}^{2+}$ (plus TTX and CNQX) was sufficient to block the action of NMDA on nondepolarized cells, NMDA was applied to brain slices from EmxGCaMP3 mice to allow us to visualize intracellular calcium concentration $\left(\left[\mathrm{Ca}^{2+}\right]_{\mathrm{i}}\right)$ changes that occur when NMDARs are activated on neurons. We found that the high $\mathrm{Mg}^{2+}$ conditions effectively blocked NMDA-triggered calcium signals in contrast to large $\left[\mathrm{Ca}^{2+}\right]_{\mathrm{i}}$ signals observed in $0 \mathrm{Mg}^{2+}$ or 0.6 $\mathrm{mm} \mathrm{Mg}{ }^{2+}$. The amplitude of the $\left[\mathrm{Ca}^{2+}\right]_{\mathrm{i}}$ signals evoked by NMDA in $0.6 \mathrm{~mm} \mathrm{Mg}^{2+}$ was not reduced by TTX and CNQX, demonstrating that block is entirely $\mathrm{Mg}^{2+}$ dependent. Additionally, since we found that probenecid ( $2 \mathrm{~mm}$ ) blocked microglial process outgrowth we tested whether probenecid would affect NMDA-induced $\left[\mathrm{Ca}^{2+}\right]_{\mathrm{i}}$ signals. Probenecid had no effect on the amplitude of the $\left[\mathrm{Ca}^{2+}\right]_{\mathrm{i}}$ signals.

\section{Discussion}

Our results demonstrate that stimulation of neuronal NMDAR triggers microglial process outgrowth as a result of ATP efflux. 


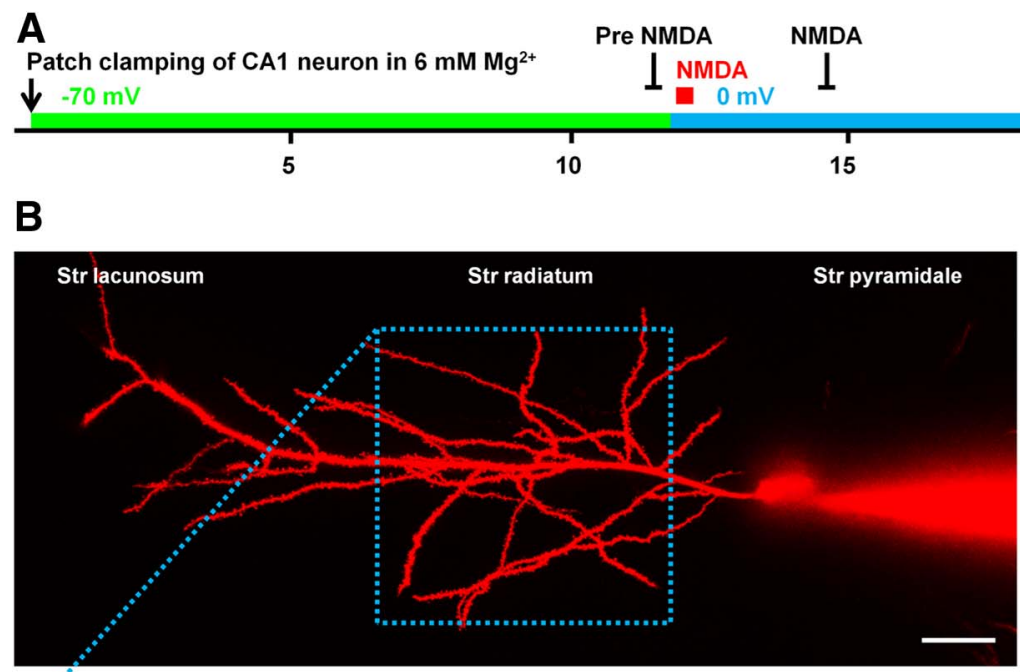

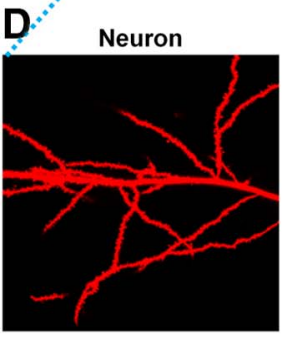

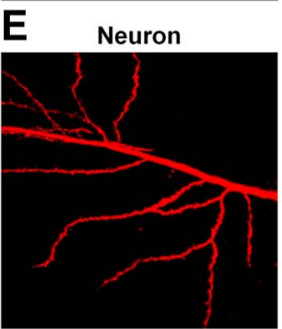

$F$

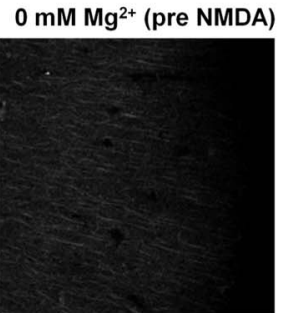

$6 \mathrm{mM} \mathrm{Mg}^{2+}($ pre NMDA $)$

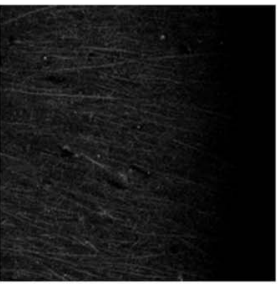

Microglia

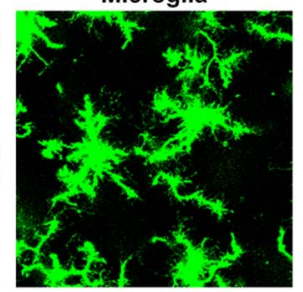

Microglia

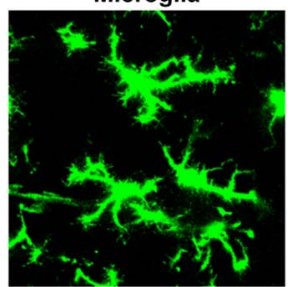

$\mathrm{mM} \mathrm{Mg}{ }^{2+}(\mathrm{NMDA})$

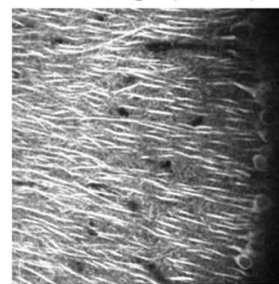

$6 \mathrm{mM} \mathrm{Mg}^{2+}(\mathrm{NMDA})$

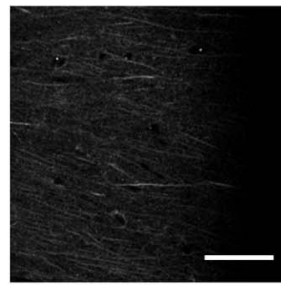

Pre NMDA

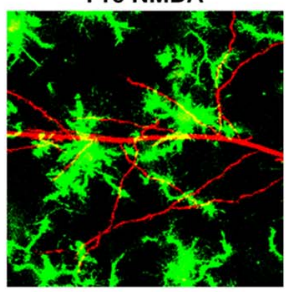

Pre NMDA

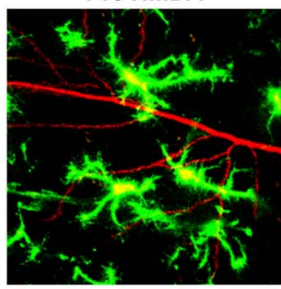

G

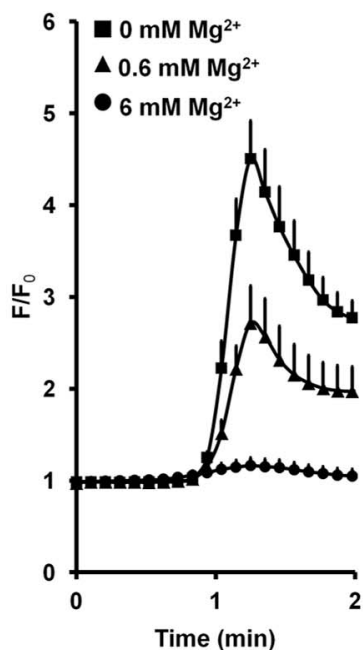

Post NMDA

1
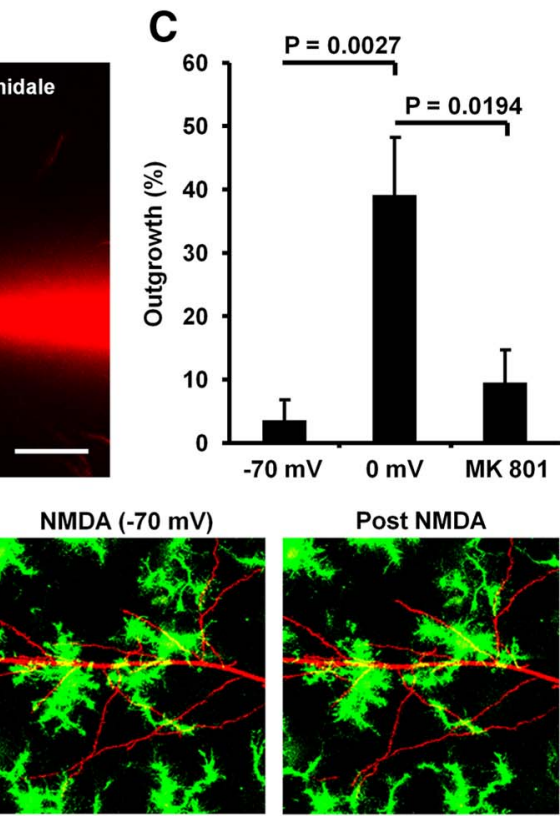

Post NMDA
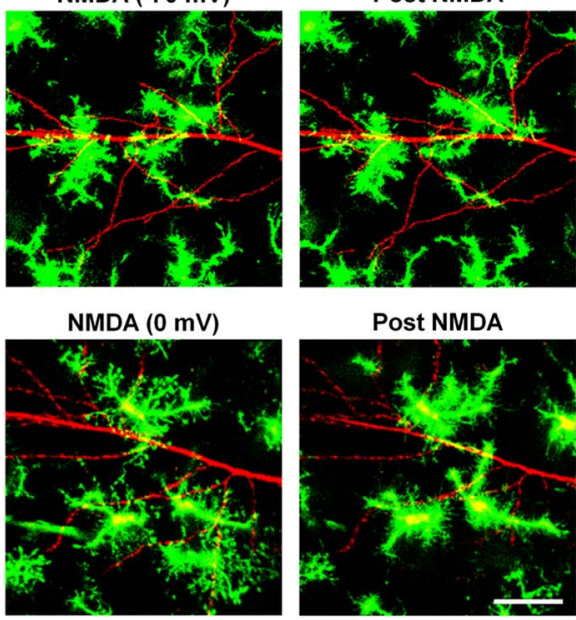

H

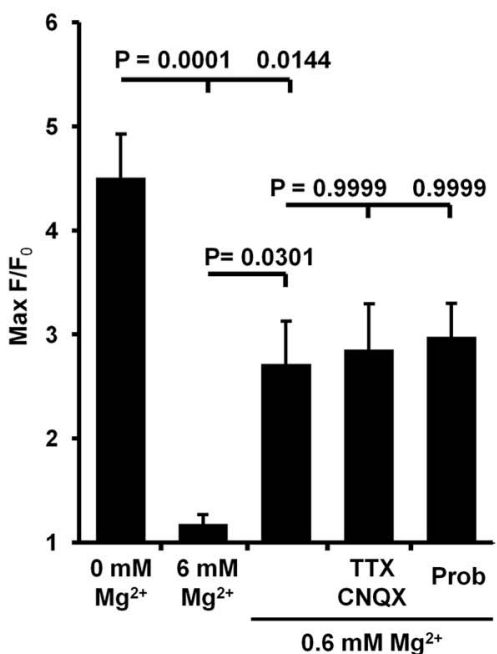

Figure 11. Microglial process outgrowth is triggered by selective NMDAR activation on a single neuron. $\boldsymbol{A}$, Time line for patch clamping, image acquisition, and depolarization during NMDA application. B, Illustration of the morphology of a patch-clamped CA1 neuron dialyzed with internal solution containing Alexa 594. z-projection of 60 images (120 $\mu \mathrm{m})$. Note the soma and the patching electrode in the stratum (Str) pyramidale. This blurry part of the image is due to light scattering because of the high cell density in Str pyramidale. Scale bar, $30 \mu \mathrm{m}$. C, Quantification of microglial process outgrowth in the presence of high extracellular $\mathrm{Mg}^{2+}(6 \mathrm{mM})$ to block NMDAR in neurons at resting membrane potential. Significant microglia outgrowth was observed only when the neuron was depolarized to allow NMDAR activation but not when the neuron was kept hyperpolarized or when the neuron was depolarized with MK-801 added to the internal solution. One-way ANOVA with Bonferroni's multiple-comparison post-test was used for statistical comparison of the three groups. $n$ values: $6(-70 \mathrm{mV}), 5(0 \mathrm{mV})$, and 4 (MK-801). D, Demonstration of the microglial morphology shown at different time points together with part of the dendritic arbor (shown in $\boldsymbol{B})$. $z$-projection of 20 images $(40 \mu \mathrm{m})$. Note that NMDA (100 $\mu \mathrm{M})$ does not trigger outgrowth when the neuron is kept hyperpolarized NMDA $(-70 \mathrm{mV})$ compared with Pre NMDA and Post NMDA. $\boldsymbol{E}$, Similar demonstration as shown in $\boldsymbol{D}$ but in this experiment the neuron was depolarized to remove its $\mathrm{Mg}^{2+}$ block before application of NMDA. Note the NMDA-triggered outgrowth NMDA $(0 \mathrm{mV})$ compared with Pre NMDA and Post NMDA. Scale bar, $30 \mu \mathrm{m}$. $\boldsymbol{F}-\boldsymbol{H}, \mathrm{NMDA}$ (Figure legend continues.) 
The outgrowth following dendritic NMDAR stimulation was abolished in the presence of APV and MK-801, indicating that it was dependent on neuronal NMDAR. The wide-spectrum purinergic inhibitor RB2 and the ectonucleotidase inhibitor ARL also blocked NMDA-triggered microglial process outgrowth, demonstrating that the outgrowth was caused by ATP and not by direct actions of NMDA itself. The mechanism underlying ATP efflux that in turn induces microglia process outgrowth was independent of Panx1 channel opening, ATP release from astrocytes via connexins, and NO generation but it was sensitive to probenecid. Finally, we show that selective activation of dendritic NMDAR on a single neuron is sufficient to trigger microglial process outgrowth.

The patterns of process outgrowth induced by NMDA were similar to the outgrowth induced by direct ATP application although there were three interesting differences. First, under our experimental conditions we found that multiple applications of NMDA were required to trigger reliable and robust outgrowth, whereas direct purinergic stimulation by a single ATP application immediately caused a pronounced outgrowth. Second, outgrowth triggered by a $1 \mathrm{~min}$ NMDA application could persist for up to $15 \mathrm{~min}$. In contrast, ATP-induced outgrowth reversed immediately after the ATP application was terminated. Third, outgrowth triggered by bath application of NMDA was nonpolarized in that the number and extension of processes were isotropic. In contrast, the outgrowth induced by bath application of ATP was polarized toward the surface of the slice.

Considering that the application of ATP immediately triggers microglial process outgrowth, we hypothesize that the requirement of multiple NMDA applications for triggering a robust microglia process outgrowth is due to progressively enhanced ATP release following multiple NMDA applications. In addition, ATP is rapidly hydrolyzed to adenosine by ectonucleotidases within the tissue (Färber et al., 2008) resulting in an immediate decline in extracellular ATP concentrations following termination of ATP application. This rapid hydrolysis of ATP also explains why the bulbous tips withdrew and the processes retracted rapidly upon removal of ATP. The protracted time course of process outgrowth (up to $15 \mathrm{~min}$ ) triggered by NMDA application likely reflects a prolonged release of ATP, which may be explained by slow NMDA washout in addition to the kinetics of the mechanisms of ATP release. We further demonstrate that the purinergic gradient generated by the extonucleotidases is crucial for directed microglia process outgrowth.

The nonpolarized outgrowth of microglial processes in response to NMDA application suggests that the extensive stimulation of NMDAR in the hippocampal dendritic region causes the release of ATP throughout the tissue. In contrast, the polarization of process outgrowth toward the surface of the slice during ATP

\footnotetext{
(Figure legend continued.) application to brain slices from Emx-GCaMP3 mice that express the calcium indicator, GCaMP3, in neurons. $\boldsymbol{F}$, Demonstration of NMDA-triggered $\mathrm{Ca}^{2+}{ }_{i}$ signals in the presence of 0 or $6 \mathrm{~mm} \mathrm{Mg}^{2+}$. Note the elevation in $\mathrm{Ca}^{2+}{ }_{\text {i }}$ in $0 \mathrm{~mm} \mathrm{Mg}^{2+}$ NMDA versus Pre NMDA compared within $6 \mathrm{~mm} \mathrm{Mg}{ }^{2+}$ NMDA versus Pre NMDA. Scale bar, $50 \mu \mathrm{m}$. G, Graphic depiction of NMDA-triggered $\mathrm{Ca}^{2+}{ }_{i}$ signals in the presence of $0,0.6$, and $6 \mathrm{~mm} \mathrm{Mg}^{2+}$ measured as $F / F_{0}$ in a $100 \times 100 \mu \mathrm{m}$ "region of interest" placed in the Str radiatum. $F=$ fluorescence intensity at time $x$ and $F_{0}=$ fluorescence intensity at time 0 . The traces were aligned for peak values. $\boldsymbol{H}$, Graphic depiction of max $F / F_{0}$ demonstrating that $6 \mathrm{~mm} \mathrm{Mg}^{2+}$ significantly blocked NMDA-triggered $\mathrm{Ca}^{2+}$ i signals compared with the large $\mathrm{Ca}^{2+}{ }_{i}$ signals that were observed in 0 $\mathrm{mm} \mathrm{Mg}^{2+}$ and $0.6 \mathrm{~mm} \mathrm{Mg}^{2+}$ conditions. The amplitude of the neuronal $\mathrm{Ca}^{2+}{ }_{i}$ signals evoked by NMDA in $0.6 \mathrm{~mm} \mathrm{Mg}{ }^{2+}$ was not reduced by TTX and CNQX. Probenecid had no effect on the NMDA-induced $\mathrm{Ca}^{2+}{ }_{i}$ signal at the concentration $(2 \mathrm{mM})$ that prevented microglia process outgrowth from NMDAR activation. One-way ANOVA with Bonferroni's multiple-comparison post-test was used for statistical comparison of the five groups, $n=3$.
}

application suggests that bath application of ATP leads to the formation of a downward ATP gradient from the surface of the slice due to in situ hydrolysis of ATP. The NMDA-triggered microglial response was not the result of excitotoxic damage because the outgrowth triggered by NMDAR stimulation was reversible. Several studies have shown that outgrowth triggered by tissue damage causes microglial processes to extend toward and adhere to the site of damage (Kim and Dustin, 2006; Eter et al., 2008; Hines et al., 2009).

Importantly, we demonstrated that stimulation of neuronal NMDAR is the initial trigger of microglial process outgrowth as outgrowth in the presence of high extracellular $\mathrm{Mg}^{2+}$ only occurs when neurons are selectively depolarized. The outgrowth triggered by NMDA application was also abolished by blocking purinergic receptors and by inhibiting hydrolysis of ATP. Thus, we conclude that microglia process outgrowth triggered by NMDA application was due to release of ATP downstream of neuronal NMDAR stimulation and not by NMDA itself even though NMDAR expression has been reported on a subset of microglia (Gottlieb and Matute, 1997; Liang et al., 2010; Murugan et al., 2011; Kaindl et al., 2012).

To investigate the expression of P2Y12 on microglia we developed a novel fixation and immunolabeling protocol (SNAPSHOT). Using SNAPSHOT we discovered that the P2Y12 receptor proteins accumulated at the bulbous tips during ATPinduced process outgrowth thereby spatially associating it with the leading edge of the extending processes.

Another key chemotactic microglial receptor is the CX3CR1 fractalkine receptor. Binding of fractalkine to CX3CR1 provides a tonic inhibitory signal that keeps the microglia in a quiescent surveillance mode (Wolf et al., 2013) and modifies the velocity of microglia processes (Liang et al., 2009). Therefore we examined whether microglial process outgrowth triggered by NMDAR stimulation was reduced or blocked in $\mathrm{CX} 3 \mathrm{CR} 1^{-1+}$ or $\mathrm{CX} 3 \mathrm{CR} 1^{+/+}$mice compared withCX3CR $1^{-/-}$. No significant differences in outgrowth were seen in time-lapse imaging of slices from CX3CR $1^{-/+}$mice or in fixed slices from CX3CR $1^{+/+}$mice using SNAPSHOT. We conclude that NMDA-triggered process outgrowth in the adult mouse was independent of CX3CR1. However, our study does not exclude the possibility that CX3CR1 might play a role during development where CX3CR1 deficiency has been demonstrated to result in reduced microglial numbers, impaired switching of GluN2B-to-GluN2A, and delays in synaptic maturation (Paolicelli et al., 2011; Hoshiko et al., 2012).

Our finding that CBX does not block process outgrowth demonstrates that the release of ATP occurs independently of Panx1 as CBX has been demonstrated in numerous studies to abolish ATP release via Panx1 (Chekeni et al., 2010; Li et al., 2011; Lohman et al., 2012). The absence of a block by CBX also excludes alternative ATP release pathways. The block of astrocytic dye coupling confirmed that CBX at these concentrations completely blocks astrocytic gap junctions that are primarily formed by connexin 43 (Dermietzel et al., 2000). Panx1 is blocked by CBX at a 10 times lower concentration than required for blockade of gap junctions (Spray et al., 2006). Therefore, the effective block of astrocyte dye coupling via gap junctions indicates that Panx1 channels were blocked under these conditions. Astrocytes have been demonstrated to release ATP through opening of connexin 43 channels due to decreased extracellular $\mathrm{Ca}^{2+}$ following high neuronal activity (Cotrina et al., 1998; Torres et al., 2012). However, the block of connexin 43-mediated ATP release by CBX (Pearson et al., 2005; Torres et al., 2012) eliminates the possible role of astrocytic hemichannels in ATP efflux following induction of high neuronal activity induced by NMDAR stimulation. We 
further demonstrated that outgrowth occurred independent of ATP-induced ATP release from astrocytes.

Using SNAPSHOT on brain slices from Panx1-deficient mice subjected to five NMDA applications, we further demonstrate that NMDA-triggered microglial process outgrowth occurs independently of Panx1 expression. Whether Panxl can play a role in neuron-microglia communication under other conditions such as necrosis or apoptosis is still to be investigated. Our results describe a pathway by which neuronal NMDAR activation mediates ATPinduced outgrowth independent of Panx1. Recent reports have indicated a functional role of Panx2 homomers in the brain, raising questions about involvement of Panx2 in our paradigm. Initial observations point toward $\mathrm{CBX}$ as being an effective inhibitor of Panx2 (Ambrosi et al., 2010; Bargiotas et al., 2011); however, more selective pharmacological agents are needed to resolve this question.

Notably, we found that the nonselective Panx1 blocker probenecid, which also inhibits several transporters of the ATPbinding cassette superfamily (e.g., organic anion transporters and multidrug resistance-associated proteins; Di Virgilio et al., 1988; Lipman et al., 1990; Potschka et al., 2004), blocked the NMDA-triggered microglial process outgrowth. It is unlikely that the effect of probenecid is due to attenuation of NMDA-induced currents as this inhibition requires concentrations 10 times higher than the concentration used in this study (Urenjak et al., 1997) and we demonstrate that $2 \mathrm{~mm}$ probenecid has no effect on NMDA-triggered calcium signals. Probenecid has previously been reported to block ATP-mediated microglial process outgrowth in the retina where outgrowth was triggered by a single bath application of AMPA or kainate (Fontainhas et al., 2011). While the discrepancy in the initial stimuli leading to ATP release might be ascribed to tissue- specific differences (retina vs hippocampus), the fact that probenecid blocked the ATP-mediated outgrowth triggered by activation of any of the three main neuronal ionotropic glutamate receptors suggests a common, yet undetermined mechanism for neuron-microglia communication.

Microglia-derived neurotrophins have been reported to promote synapse formation (Parkhurst et al., 2013) and ramified microglia limit neuronal degeneration following excessive NMDAR stimulation (Vinet et al., 2012). Our results demonstrate that activation of neuronal NMDAR triggers the release of ATP via a mechanism that is independent of cell death or Panx1 opening but is sensitive to probenecid. We suggest that ATP is an important molecular cue that enhances the surveillance exerted by microglial processes within the regions of the dendritic arbors following NMDAR activation on neuronal dendrites. The functional roles of this neuronal-evoked enhanced surveillance are undetermined but could potentially lead to reciprocal communication via local release of neurotrophins. In conclusion, these findings demonstrate a form of neuron- microglia communication that is initiated by dendritic NMDAR activation in the adult brain.

\section{References}

Ambrosi C, Gassmann O, Pranskevich JN, Boassa D, Smock A, Wang J, Dahl G, Steinem C, Sosinsky GE (2010) Pannexin1 and Pannexin2 channels show quaternary similarities to connexons and different oligomerization numbers from each other. J Biol Chem 285:24420-24431. CrossRef Medline

Baraldi PG, del Carmen Nuñez M, Morelli A, Falzoni S, Di Virgilio F, Romagnoli R (2003) Synthesis and biological activity of N-arylpiperazinemodified analogues of KN-62, a potent antagonist of the purinergic P2X7 receptor. J Med Chem 46:1318-1329. CrossRef Medline

Bargiotas P, Krenz A, Hormuzdi SG, Ridder DA, Herb A, Barakat W, Penuela S, von Engelhardt J, Monyer H, Schwaninger M (2011) Pannexins in ischemia-induced neurodegeneration. Proc Natl Acad Sci U S A 108: 20772-20777. CrossRef Medline

Baroja-Mazo A, Barberà-Cremades M, Pelegrín P (2013) The participation of plasma membrane hemichannels to purinergic signaling. Biochim Biophys Acta 1828:79-93. CrossRef Medline

Bialas AR, Stevens B (2013) TGF-beta signaling regulates neuronal C1q expression and developmental synaptic refinement. Nat Neurosci 16:17731782. CrossRef Medline

Castañeda-Castellanos DR, Flint AC, Kriegstein AR (2006) Blind patch clamp recordings in embryonic and adult mammalian brain slices. Nat Protoc 1:532-542. CrossRef Medline

Chekeni FB, Elliott MR, Sandilos JK, Walk SF, Kinchen JM, Lazarowski ER, Armstrong AJ, Penuela S, Laird DW, Salvesen GS, Isakson BE, Bayliss DA, Ravichandran KS (2010) Pannexin 1 channels mediate 'find-me' signal release and membrane permeability during apoptosis. Nature 467:863867. CrossRef Medline

Christopherson KS, Hillier BJ, Lim WA, Bredt DS (1999) PSD-95 assembles a ternary complex with the N-methyl-D-aspartic acid receptor and a bivalent neuronal NO synthase PDZ domain. J Biol Chem 274:2746727473. CrossRef Medline

Cotrina ML, Lin JH, Alves-Rodrigues A, Liu S, Li J, Azmi-Ghadimi H, Kang J, Naus CC, Nedergaard M (1998) Connexins regulate calcium signaling by controlling ATP release. Proc Natl Acad Sci U S A 95:15735-15740. CrossRef Medline

d'Anglemont de Tassigny X, Campagne C, Dehouck B, Leroy D, Holstein GR, Beauvillain JC, Buée-Scherrer V, Prevot V (2007) Coupling of neuronal nitric oxide synthase to NMDA receptors via postsynaptic density-95 depends on estrogen and contributes to the central control of adult female reproduction. J Neurosci 27:6103-6114. CrossRef Medline

Davalos D, Grutzendler J, Yang G, Kim JV, Zuo Y, Jung S, Littman DR, Dustin ML, Gan WB (2005) ATP mediates rapid microglial response to local brain injury in vivo. Nat Neurosci 8:752-758. CrossRef Medline

Dermietzel R, Gao Y, Scemes E, Vieira D, Urban M, Kremer M, Bennett MV, Spray DC (2000) Connexin43 null mice reveal that astrocytes express multiple connexins. Brain Res Brain Res Rev 32:45-56. CrossRef Medline

Dibaj P, Nadrigny F, Steffens H, Scheller A, Hirrlinger J, Schomburg ED, Neusch C, KirchhoffF (2010) NO mediates microglial response to acute spinal cord injury under ATP control in vivo. Glia 58:1133-1144. CrossRef Medline

Di Virgilio F, Fasolato C, Steinberg TH (1988) Inhibitors of membrane transport system for organic anions block fura-2 excretion from PC12 and N2A cells. Biochem J 256:959-963. Medline

Elliott MR, Chekeni FB, Trampont PC, Lazarowski ER, Kadl A, Walk SF, Park D, Woodson RI, Ostankovich M, Sharma P, Lysiak JJ, Harden TK, Leitinger N, Ravichandran KS (2009) Nucleotides released by apoptotic cells act as a find-me signal to promote phagocytic clearance. Nature 461:282-286. CrossRef Medline

Eter N, Engel DR, Meyer L, Helb HM, Roth F, Maurer J, Holz FG, Kurts C (2008) In vivo visualization of dendritic cells, macrophages, and microglial cells responding to laser-induced damage in the fundus of the eye. Invest Ophthalmol Vis Sci 49:3649-3658. CrossRef Medline

Färber K, Markworth S, Pannasch U, Nolte C, Prinz V, Kronenberg G, Gertz K, Endres M, Bechmann I, Enjyoji K, Robson SC, Kettenmann H (2008) The ectonucleotidase cd39/ENTPDase1 modulates purinergic-mediated microglial migration. Glia 56:331-341. CrossRef Medline

Fontainhas AM, Wang M, Liang KJ, Chen S, Mettu P, Damani M, Fariss RN, Li W, Wong WT (2011) Microglial morphology and dynamic behavior is regulated by ionotropic glutamatergic and GABAergic neurotransmission. PLoS One 6:e15973. CrossRef Medline

Gorski JA, Talley T, Qiu M, Puelles L, Rubenstein JL, Jones KR (2002) Cortical excitatory neurons and glia, but not GABAergic neurons, are produced in the Emx1-expressing lineage. J Neurosci 22:6309-6314. Medline

Gottlieb M, Matute C (1997) Expression of ionotropic glutamate receptor subunits in glial cells of the hippocampal CA1 area following transient forebrain ischemia. J Cereb Blood Flow Metab 17:290-300. Medline

Haynes SE, Hollopeter G, Yang G, Kurpius D, Dailey ME, Gan WB, Julius D (2006) The P2Y12 receptor regulates microglial activation by extracellular nucleotides. Nat Neurosci 9:1512-1519. CrossRef Medline

Hefendehl JK, Milford D, Eicke D, Wegenast-Braun BM, Calhoun ME, Grathwohl SA, Jucker M, Liebig C (2012) Repeatable target localization for long-term in vivo imaging of mice with 2-photon microscopy. J Neurosci Methods 205:357-363. CrossRef Medline

Hickman SE, Kingery ND, Ohsumi TK, Borowsky ML, Wang LC, Means TK, El Khoury J (2013) The microglial sensome revealed by direct RNA sequencing. Nat Neurosci 16:1896-1905. CrossRef Medline

Hines DJ, Hines RM, Mulligan SJ, Macvicar BA (2009) Microglia processes 
block the spread of damage in the brain and require functional chloride channels. Glia 57:1610-1618. CrossRef Medline

Hoffmann K, Sixel U, Di Pasquale F, von Kügelgen I (2008) Involvement of basic amino acid residues in transmembrane regions 6 and 7 in agonist and antagonist recognition of the human platelet P2Y(12)-receptor. Biochem Pharmacol 76:1201-1213. CrossRef Medline

Hoshiko M, Arnoux I, Avignone E, Yamamoto N, Audinat E (2012) Deficiency of the microglial receptor CX3CR1 impairs postnatal functional development of thalamocortical synapses in the barrel cortex. J Neurosci 32:15106-15111. CrossRef Medline

Huang YJ, Maruyama Y, Dvoryanchikov G, Pereira E, Chaudhari N, Roper SD (2007) The role of pannexin 1 hemichannels in ATP release and cell-cell communication in mouse taste buds. Proc Natl Acad Sci U S A 104:6436-6441. CrossRef Medline

Imai Y, Ibata I, Ito D, Ohsawa K, Kohsaka S (1996) A novel gene ibal in the major histocompatibility complex class III region encoding an EF hand protein expressed in a monocytic lineage. Biochem Biophys Res Commun 224:855-862. CrossRef Medline

Jung S, Aliberti J, Graemmel P, Sunshine MJ, Kreutzberg GW, Sher A, Littman DR (2000) Analysis of fractalkine receptor CX(3)CR1 function by targeted deletion and green fluorescent protein reporter gene insertion. Mol Cell Biol 20:4106-4114. CrossRef Medline

Kafitz KW, Meier SD, Stephan J, Rose CR (2008) Developmental profile and properties of sulforhodamine 101-Labeled glial cells in acute brain slices of rat hippocampus. J Neurosci Methods 169:84-92. CrossRef Medline

Kaindl AM, Degos V, Peineau S, Gouadon E, Chhor V, Loron G, Le Charpentier T, Josserand J, Ali C, Vivien D, Collingridge GL, Lombet A, Issa L, Rene F, Loeffler JP, Kavelaars A, Verney C, Mantz J, Gressens P (2012) Activation of microglial N-methyl-D-aspartate receptors triggers inflammation and neuronal cell death in the developing and mature brain. Ann Neurol 72:536-549. CrossRef Medline

Kim JV, Dustin ML (2006) Innate response to focal necrotic injury inside the blood-brain barrier. J Immunol 177:5269-5277. CrossRef Medline

Kozlowski C, Weimer RM (2012) An automated method to quantify microglia morphology and application to monitor activation state longitudinally in vivo. PLoS One 7:e31814. CrossRef Medline

Liang J, Takeuchi H, Jin S, Noda M, Li H, Doi Y, Kawanokuchi J, Sonobe Y, Mizuno T, Suzumura A (2010) Glutamate induces neurotrophic factor production from microglia via protein kinase $\mathrm{C}$ pathway. Brain Res 1322: 8-23. CrossRef Medline

Liang KJ, Lee JE, Wang YD, Ma W, Fontainhas AM, Fariss RN, Wong WT (2009) Regulation of dynamic behavior of retinal microglia by CX3CR1 signaling. Invest Ophthalmol Vis Sci 50:4444-4451. CrossRef Medline

Li S, Bjelobaba I, Yan Z, Kucka M, Tomic M, Stojilkovic SS (2011) Expression and roles of pannexins in ATP release in the pituitary gland. Endocrinology 152:2342-2352. CrossRef Medline

Li Y, Du XF, Liu CS, Wen ZL, Du JL (2012) Reciprocal regulation between resting microglial dynamics and neuronal activity in vivo. Dev Cell 23: 1189-1202. CrossRef Medline

Lipman BJ, Silverstein SC, Steinberg TH (1990) Organic anion transport in macrophage membrane vesicles. J Biol Chem 265:2142-2147. Medline

Lohman AW, Weaver JL, Billaud M, Sandilos JK, Griffiths R, Straub AC, Penuela S, Leitinger N, Laird DW, Bayliss DA, Isakson BE (2012) S-nitrosylation inhibits pannexin 1 channel function. J Biol Chem 287: 39602-39612. CrossRef Medline

Murugan M, Sivakumar V, Lu J, Ling EA, Kaur C (2011) Expression of N-methyl D-aspartate receptor subunits in amoeboid microglia mediates production of nitric oxide via NF-kappaB signaling pathway and oligodendrocyte cell death in hypoxic postnatal rats. Glia 59:521-539. CrossRef Medline

Nimmerjahn A, Kirchhoff F, Kerr JN, Helmchen F (2004) Sulforhodamine 101 as a specific marker of astroglia in the neocortex in vivo. Nat Methods 1:31-37. CrossRef Medline

Nimmerjahn A, Kirchhoff F, Helmchen F (2005) Resting microglial cells are highly dynamic surveillants of brain parenchyma in vivo. Science 308: 1314-1318. CrossRef Medline

Ohsawa K, Irino Y, Sanagi T, Nakamura Y, Suzuki E, Inoue K, Kohsaka S (2010) $\mathrm{P} 2 \mathrm{Y} 12$ receptor-mediated integrin-betal activation regulates microglial process extension induced by ATP. Glia 58:790-801. CrossRef Medline

Ohsawa K, Sanagi T, Nakamura Y, Suzuki E, Inoue K, Kohsaka S (2012) Adenosine A3 receptor is involved in ADP-induced microglial process extension and migration. J Neurochem 121:217-227. CrossRef Medline
Orr AG, Orr AL, Li XJ, Gross RE, Traynelis SF (2009) Adenosine A(2A) receptor mediates microglial process retraction. Nat Neurosci 12:872878. CrossRef Medline

Paolicelli RC, Bolasco G, Pagani F, Maggi L, Scianni M, Panzanelli P, Giustetto M, Ferreira TA, Guiducci E, Dumas L, Ragozzino D, Gross CT (2011) Synaptic pruning by microglia is necessary for normal brain development. Science 333:1456-1458. CrossRef Medline

Parkhurst CN, Yang G, Ninan I, Savas JN, Yates JR 3rd, Lafaille JJ, Hempstead BL, Littman DR, Gan WB (2013) Microglia promote learningdependent synapse formation through brain-derived neurotrophic factor. Cell 155:1596-1609. CrossRef Medline

Pascual O, Ben Achour S, Rostaing P, Triller A, Bessis A (2012) Microglia activation triggers astrocyte-mediated modulation of excitatory neurotransmission. Proc Natl Acad Sci U S A 109:E197-E205. CrossRef Medline

Pearson RA, Dale N, Llaudet E, Mobbs P (2005) ATP released via gap junction hemichannels from the pigment epithelium regulates neural retinal progenitor proliferation. Neuron 46:731-744. CrossRef Medline

Penuela S, Bhalla R, Nag K, Laird DW (2009) Glycosylation regulates pannexin intermixing and cellular localization. Mol Biol Cell 20:4313-4323. CrossRef Medline

Potschka H, Baltes S, Löscher W (2004) Inhibition of multidrug transporters by verapamil or probenecid does not alter blood-brain barrier penetration of levetiracetam in rats. Epilepsy Res 58:85-91. CrossRef Medline

Qu Y, Misaghi S, Newton K, Gilmour LL, Louie S, Cupp JE, Dubyak GR, Hackos D, Dixit VM (2011) Pannexin-1 is required for ATP release during apoptosis but not for inflammasome activation. J Immunol 186:65536561. CrossRef Medline

Sasaki Y, Hoshi M, Akazawa C, Nakamura Y, Tsuzuki H, Inoue K, Kohsaka S (2003) Selective expression of Gi/o-coupled ATP receptor P2Y12 in microglia in rat brain. Glia 44:242-250. CrossRef Medline

Sattler R, Xiong Z, Lu WY, Hafner M, MacDonald JF, Tymianski M (1999) Specific coupling of NMDA receptor activation to nitric oxide neurotoxicity by PSD-95 protein. Science 284:1845-1848. CrossRef Medline

Schafer DP, Lehrman EK, Kautzman AG, Koyama R, Mardinly AR, Yamasaki R, Ransohoff RM, Greenberg ME, Barres BA, Stevens B (2012) Microglia sculpt postnatal neural circuits in an activity and complementdependent manner. Neuron 74:691-705. CrossRef Medline

Sieger D, Moritz C, Ziegenhals T, Prykhozhij S, Peri F (2012) Long-range $\mathrm{Ca} 2+$ waves transmit brain-damage signals to microglia. Dev Cell 22: 1138-1148. CrossRef Medline

Silverman W, Locovei S, Dahl G (2008) Probenecid, a gout remedy, inhibits pannexin 1 channels. Am J Physiol Cell Physiol 295:C761-C767. CrossRef Medline

Spray DC, YeZC, Ransom BR (2006) Functional connexin "hemichannels": a critical appraisal. Glia 54:758-773. CrossRef Medline

Thompson RJ, Zhou N, MacVicar BA (2006) Ischemia opens neuronal gap junction hemichannels. Science 312:924-927. CrossRef Medline

Thompson RJ, Jackson MF, Olah ME, Rungta RL, Hines DJ, Beazely MA, MacDonald JF, MacVicar BA (2008) Activation of pannexin-1 hemichannels augments aberrant bursting in the hippocampus. Science 322: 1555-1559. CrossRef Medline

Torres A, Wang F, Xu Q, Fujita T, Dobrowolski R, Willecke K, Takano T, Nedergaard M (2012) Extracellular $\mathrm{Ca}(2)(+)$ acts as a mediator of communication from neurons to glia. Sci Signal 5:ra8. CrossRef Medline

Tremblay MÈ, Lowery RL, Majewska AK (2010) Microglial interactions with synapses are modulated by visual experience. PLoS Biol 8:e1000527. CrossRef Medline

Urenjak J, Obrenovitch TP, Zilkha E (1997) Effect of probenecid on depolarizations evoked by $\mathrm{N}$-methyl-D-aspartate (NMDA) in the rat striatum. Naunyn Schmiedebergs Arch Pharmacol 355:36-42. Medline

Vinet J, Weering HR, Heinrich A, Kälin RE, Wegner A, Brouwer N, Heppner FL, Rooijen Nv, Boddeke HW, Biber K (2012) Neuroprotective function for ramified microglia in hippocampal excitotoxicity. J Neuroinflammation 9:27. CrossRef Medline

Wake H, Moorhouse AJ, Jinno S, Kohsaka S, Nabekura J (2009) Resting microglia directly monitor the functional state of synapses in vivo and determine the fate of ischemic terminals. J Neurosci 29:3974-3980. CrossRef Medline

Wolf Y, Yona S, Kim KW, Jung S (2013) Microglia, seen from the CX3CR1 angle. Front Cell Neurosci 7:26. CrossRef Medline

Wu LJ, Zhuo M (2008) Resting microglial motility is independent of synaptic plasticity in mammalian brain. J Neurophysiol 99:2026-2032. CrossRef Medline 